\title{
EAGER TO ENGAGE: YOUNG NIGERIAN CHILDREN'S INTERACTIONS WITH NOVEL PLAY MATERIALS
}

by

Wendy Suh, BSc, University of Toronto, 2006,

\author{
A Major Research Paper \\ presented to Ryerson University
}

\author{
in partial fulfillment of the \\ requirements for the degree of \\ Master of Arts \\ in the Program of \\ Early Childhood Studies
}

Toronto, Ontario, Canada, 2016

(C) Wendy Suh 2016 


\section{AUTHOR'S DECLARATION FOR ELECTRONIC SUBMISSION OF A MRP}

I hereby declare that I am the sole author of this MRP. This is a true copy of the MRP, including any required final revisions.

I authorize Ryerson University to lend this MRP to other institutions or individuals for the purpose of scholarly research

I further authorize Ryerson University to reproduce this MRP by photocopying or by other means, in total or in part, at the request of other institutions or individuals for the purpose of scholarly research.

I understand that my MRP may be made electronically available to the public. 


\section{ABSTRACT \\ EAGER TO ENGAGE: YOUNG NIGERIAN CHILDREN'S INTERACTIONS WITH NOVEL PLAY MATERIALS Master of Arts \\ Wendy Suh \\ Program of Early Childhood Studies \\ Ryerson University}

The purpose of this study was to observe, analyze, and document young Nigerian children’s interactions with novel play materials at their crèche. To date, limited studies have examined Nigerian infants' and toddlers' independent engagement with novel play materials. The children’s exploratory and play behaviours—cognitive and social play—were observed. An a priori coding scheme was used to simultaneously analyze cognitive and social play behaviours in the children, eight participants between 7- and 24-months of age. Over the course of four weeks, children were introduced to 11 novel play materials. Observed cognitive play behaviours included functional play, pretend play and constructive play, while social play behaviours consisted of solitary, parallel and simple social play. Although the results showed developmental progression in exploration and play, the varying degree of novelty of the play materials may have influenced children's exploration and play. Despite these findings, children exhibited various exploratory and play behaviours with the introduction of play materials in a setting in which there were none.

Key words: cognitive play, social play, exploration, play materials, Nigerian, young children 


\section{ACKNOWLEDGEMENTS}

I would first like to thank my co-supervisors, Dr. Kathleen Peets and Dr. Aurelia Di Santo. I was fortunate to have two brilliant supervisors who provided their expert guidance and generous support. Words cannot express my gratitude. I would also like to thank Dr. Mehrunnisa Ali who accepted the responsibility of $2^{\text {nd }}$ reader and invested her time to review my paper.

Next, I would like to thank those who made this research in Nigeria possible. I am grateful to ECDI for giving me this opportunity and for guiding my study, specifically in the design and introduction of the play materials in ways that were culturally respectful. I would like to acknowledge Adizat who spent countless hours developing the play materials. Her dedication to the children is truly inspirational. I would also like to acknowledge Ryerson's School of Early Childhood Studies, Ryerson's Faculty of Community Services, and Ryerson International for the grants, which provided much needed financial assistance for this trip. I would also like to thank those in Nigeria who worked tirelessly to make this research possible. They welcomed us with open arms and embraced this collaboration. I am grateful to the children at the crèche who gave me a glimpse into their play, reminding me to remain playful. I would be remiss if I did not acknowledge my team—Kathleen, Patricia, Adizat, Jenna, and Samantha. I am so lucky to have shared in the laughs, tears, and suya with you all.

I would also like to thank my wonderful friends and colleagues who continued to send their words of encouragement down to the last days of writing this paper. I am grateful for your support. I would especially like to thank Sami for his unabating belief in me, for picking me up from the grad lounge too many nights past midnight, and most importantly for providing endless laughs. I needed those!

Finally, I would like to thank my family: my mom and dad for their confidence in me and all my pursuits; my sisters, Sarah and Erica, for their unconditional love and support (and for proofreading my work!); and my brother, Matthew, for being born. He was the first baby that I loved. 


\section{DEDICATION}

This Major Research Paper is dedicated to the two lovely caregivers at the crèche in Abuja, Nigeria, who not only taught me how to "back" a baby, but most importantly, who believed in this study and our joint vision. Without their dedication to and care for the children, I am certain,

I would not have been able to carry out this research. Their love and hard work did not go unnoticed. I am grateful from the bottom of my heart.

$\sim$ Wendy Suh 


\section{TABLE OF CONTENTS}

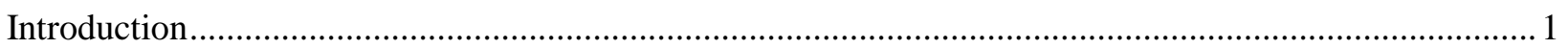

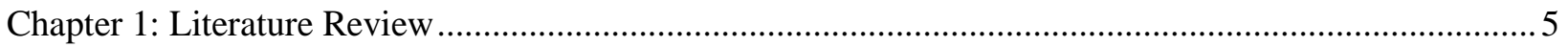

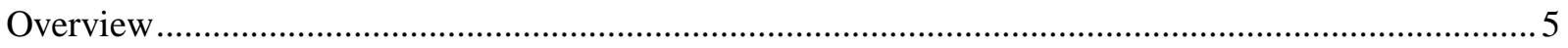

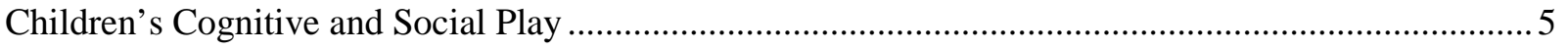

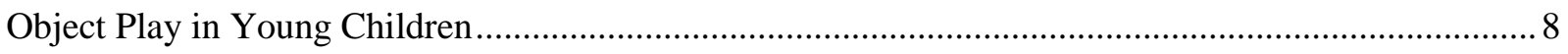

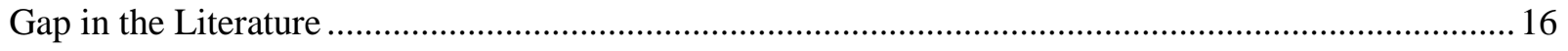

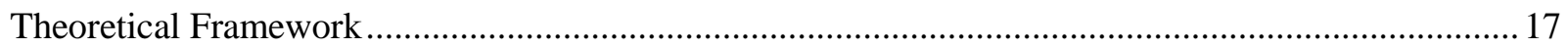

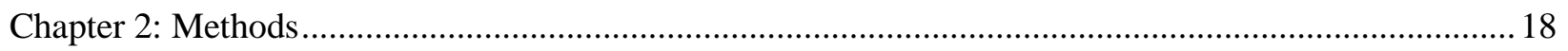

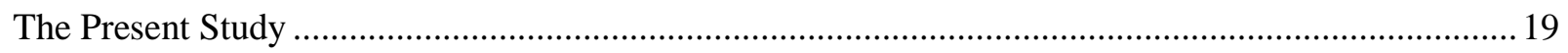

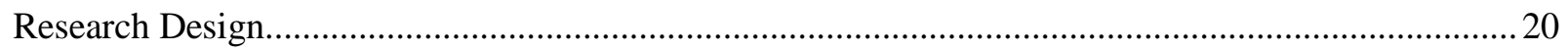

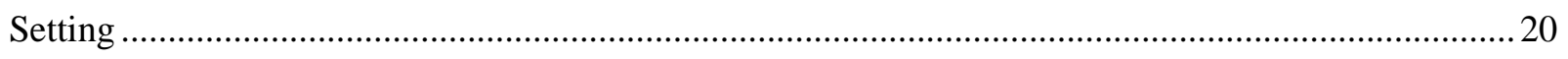

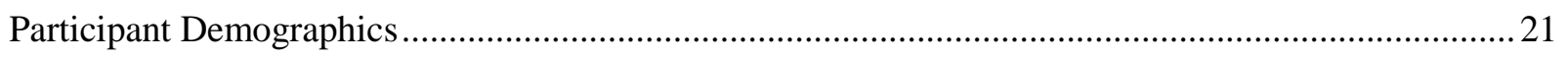

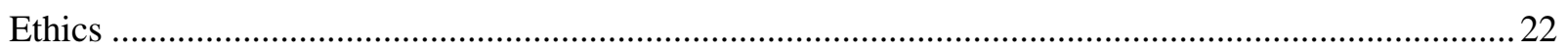

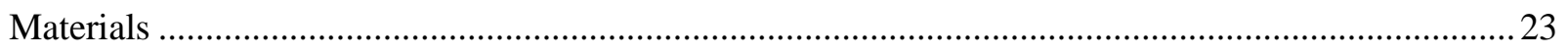

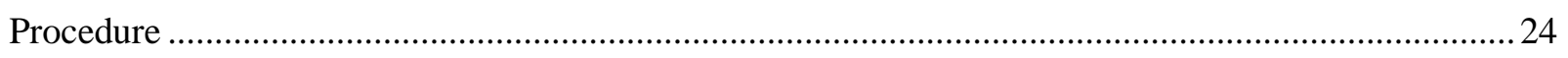

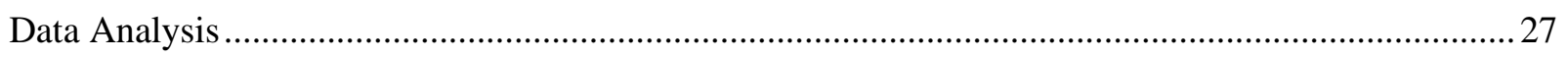

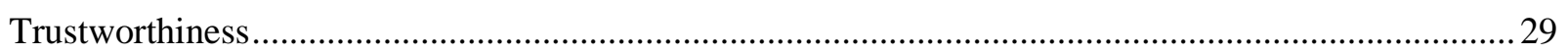

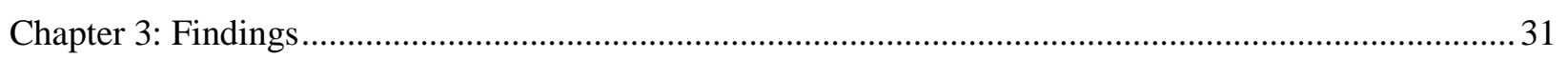

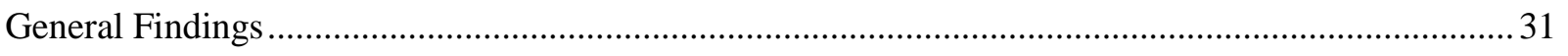

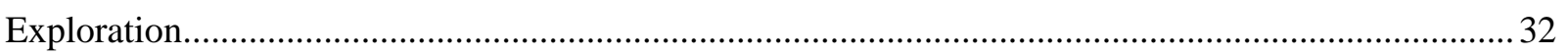

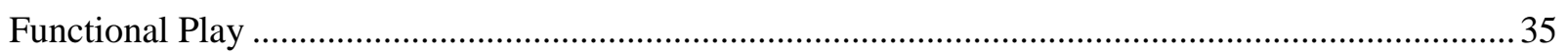

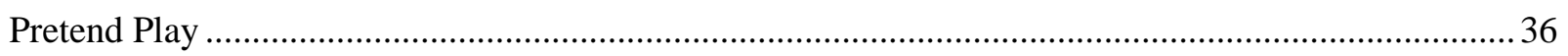

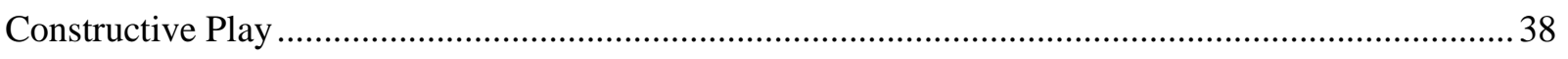

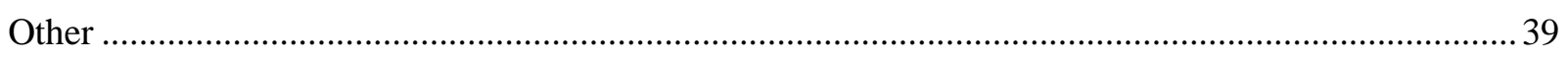

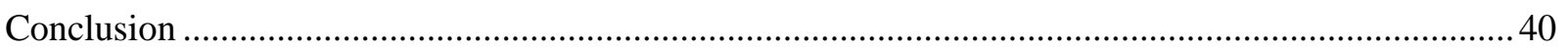

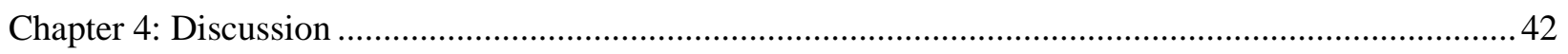

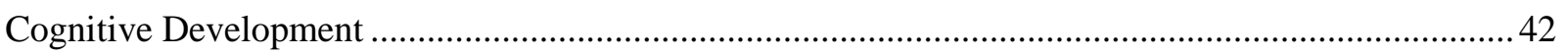

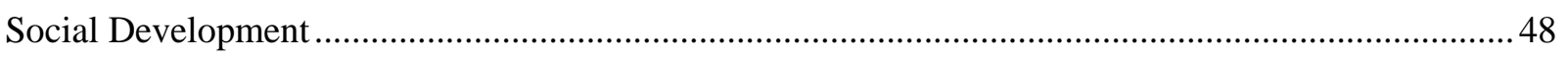

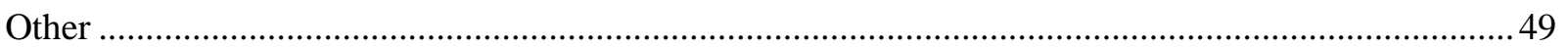

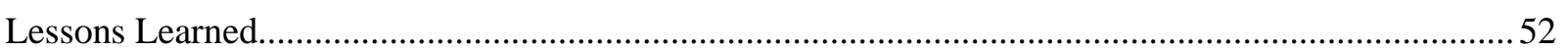

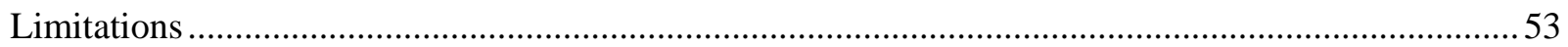




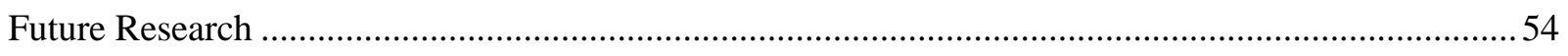

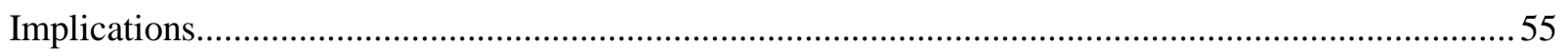

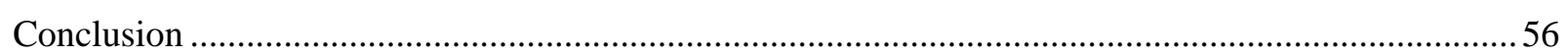

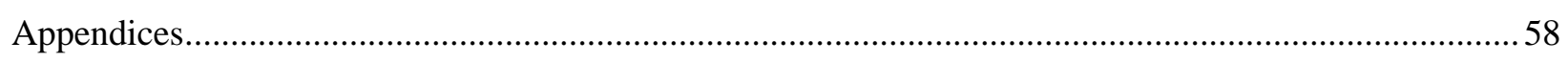

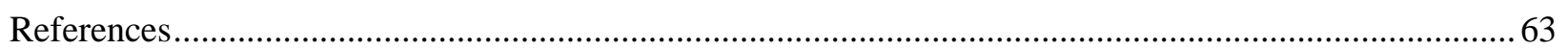




\section{LIST OF APPENDICES}

Appendix A: Figure 1 - Crèche Floor Plan (Abuja, Nigeria) ................................................ 58

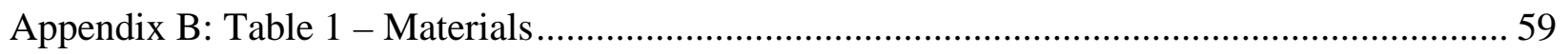

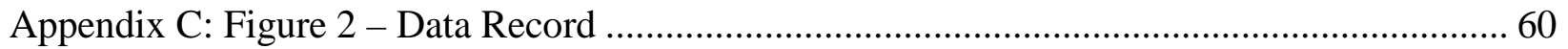

Appendix D: Figure 3 - Object Play Coding Scheme ....................................................... 61

Appendix E: Table 2 - Frequencies of Coded Behaviour ......................................................... 62 


\section{Introduction}

A child's impulse to play is innate and is so fundamental to healthy development that the United Nations Convention on the Rights of the Child has deemed it a right of childhood (UNCRC, Article 31, 1989). Despite the universality of play, it is a difficult concept to define. According to Cambridge Dictionary, play is defined as “an activity that is not serious but done for enjoyment, especially when children enjoy themselves with toys and games” (Cambridge Dictionary, 2016). As seen in Nicholson et al.'s (2014) study, children defined play as playing at someone’s house with toys. For the young American child, play is often associated with toys, which is unsurprising as American children procure more than 40\% of the world's toys even though they make up just 4\% of the world's population (Butler \& Gilson, 2016). However, one cannot assume that all children or adults would define play the same way.

Defining culture is equally as challenging as defining play. In the context of children and childhoods, culture is often referred to as a set of customs, practices, and beliefs that shape children’s lives (Harkness, 2002). Many would argue that play is a universal and natural phenomenon, but how play unfolds, particularly in an early years setting, differs across cultures (Pellegrini, 2009). In Ontario, Canada, for example, the framework for education and care for the early years is called Early Learning for Every Child Today (ELECT, 2007) and is a play-based learning framework. Early learning centres offer an assortment of play materials with which young children can engage. Recently in the USA the support for play-based education has been revived and even garnered the attention of venture capitalists who have invested \$1.6 million USD in seed funding for Tinkergarten Inc., a play-based program whose pedagogical philosophy is rooted in outdoor play (Chernova, 2016). More parents, caregivers, educators, and evidently investors, believe that play is crucial for young children’s learning. For example, a study 
conducted in two early childhood settings in Guatemala (each from different socioeconomic backgrounds) showed that both educators and parents believed in the benefits of a play-based curriculum for young children (Cooney, 2004). Similar findings were seen in studies with educators in China, Korea, and Japan (Ishigaki \& Lin, 1999). When, or if, this shift in belief translates to a shift in educational policy for the early years remains to be seen. However, there have been policy changes in early childhood education in many countries that do reflect this more recently accepted notion that the early years’ programs should be play-based. For example, Nigeria has recently incorporated the early years into its national education curriculum with a framework grounded in play-based learning. As the present study was conducted in Nigeria, the current climate of early childhood care and education in Nigeria will be discussed.

In 2007, the Nigerian Educational Research and Development Council (NERDC) in collaboration with UNICEF developed the National Early Childhood Curriculum for Ages 0-5 Years. The curriculum is divided according to children 0-36 months of age and 37-60 months of age. The Nigerian curriculum is categorized according to domains of child development, such as physical, cognitive, social, and psychosocial; as well as other culturally relevant themes, such as nutrition, health, sanitation, safety, and protection issues. In this national document, an extensive list of play and learning materials is outlined under the domains of cognitive and social development, with an emphasis on playful learning and exploration (NECC, 2007). In spite of these formal policy changes, implementation of such practices and principles have been challenging in Nigeria, with many of the criticisms directed at the lack of programs available, the lack of qualified early childhood educators, and the lack of play and recreational materials (Ige, 2011; Ogunyemi \& Ragpot, 2015). 
Regardless of people's reluctance to believe in the importance of children's play or governments' unwillingness to support play-based education, growing research on children's play suggests it is essential for learning, particularly in the areas of social and cognitive development (Hirsh-Pasek \& Golinkoff, 2008). Both current and past findings regarding children's play as a mechanism of learning stem from the vast research on children, their behaviours and the objects they use. Playing with objects is a prevalent activity for children of all ages. Such play could involve objects of varying sizes, such as small blocks or large balls; materials, such as plush stuffed animals or hard marbles; and complexities, such as wooden puzzles or intricate gadgets with knobs and buttons. However, play with objects may also involve materials and supplies found in nature or around the home. Many studies have documented developmental stages of object play, in which the materials often increase in complexity along with the child's play with them (Hutt, 1979; Lockman \& McHale, 1989). In essence, according to many studies conducted in Western societies, there is a distinction between the object play of infants, toddlers, and preschooler: infants mainly explore, while toddlers and preschoolers engage in play that is more manipulative and symbolic in nature (Morgenthaler, 2006).

Most studies on children's object play, however, have focused on populations from Western societies. Differing cultural and social contexts, including object play either alone or with others, affect children's development. To the best of my knowledge, a study has not been conducted in Nigeria documenting the introduction of play materials to infants and toddlers outside that of a controlled experiment. Therefore, in hopes of contributing to this small body of research regarding Nigerian early childhood development and play, this study will examine a group of young Nigerian children's interactions with novel play materials in their child care 
program. For the purposes of this paper, the definition of play presented by Fromberg and Bergen (2006) will be used: play is symbolic (represents reality in "what if" or "as if" terms); meaningful (connects experiences); active (involves actions including imagination); pleasurable (brings satisfaction even when engaged seriously in an activity); intrinsically motivated (fulfils one’s curiosity, mastery); rule-governed (remains restricted, implicitly or explicitly), and episodic (changes with spontaneously emerging or shifting goals). Play differs from exploration, which focuses on the properties of an object or a situation (Collard, 1979). The distinction is made between the two based on the child's actions (see Chapter 1 for definitions). Play materials refer to any object (human-made or natural) with which the child plays. This paper will describe the young Nigerian children's interactions with novel play materials that are introduced to them at their child care program in relation to cognitive and social play behaviours. The paper will also include implications for early childhood educators and caregivers as well as recommendations for future research. It is hoped this information can be used to provide a deeper understanding of children's varied needs, experiences, and interactions in their child care program in order to better support children’s learning and development in the early years. 


\section{Chapter 1: Literature Review}

\section{Overview}

This chapter is divided into three sections. First, I will discuss the well-established theories of cognitive and social play. Next, I will examine studies on children's play with objects and play materials in both Western and non-Western societies as they relate to cognitive and social development. Finally, I will conclude the chapter by identifying gaps in the literature and presenting the theoretical framework that shaped this study.

\section{Children's Cognitive and Social Play}

Childhood is a time for exploring the world and gaining some understanding of how things work and function. Observing children during the first years of their lives reveals patterns of behaviour that offer a glimpse into their early mental processes and has long been a tool used by the earliest child development researchers to gain insight into children's thinking (Piaget, 1962; Smilansky, 1968). Thus, it is believed that children need plentiful experiences with different objects and people for optimal cognitive development, as these experiences have the potential to influence the rapidly growing brain (Kotulak, 1997).

Piaget's (1962) cognitive theory states that cognitive development occurs as a result of children's interactions and experiences with their environment, including various objects. As children get older and accumulate many more experiences, they use these experiences to make sense of the world around them. Many of the experiences in children's lives include social interactions with other people. The extent of such social interactions depends on various factors including age, culture, and individual preference, to name but a few. Parten (1932) referred to social interactions within a group setting as social participation and showed that age, among other factors, affects the types of social participation in which children engage. Many studies 
have examined the unique interplay between social interactions and development (Bigelow, MacLean \& Proctor, 2004; Eckerman \& Whatley, 1977; Jacobson, 1981). Thus, both cognitive theory and the theory of social participation intersect with play to influence children's development.

Play has long been recognized as an essential tool in the cognitive development of children. Play behaviours have been categorized based on structural features: functional, constructive, and pretend, as well as games with rules (Piaget, 1962; Smilansky, 1968). Smilansky's definitions (and current modifications) of these terms are described below.

Cognitive Play. Functional play refers to children's repeated or imitated actions that are exhibited "simply for the enjoyment of the physical sensation it creates" (Rubin, 2001, p. 3). Some examples of functional play include repeatedly filling a cup with water and pouring it out, sorting or classifying objects or toys, and making a clicking sound with one's tongue.

Constructive play involves playful creation, for example, of a pattern, a robot, or a painting. A child engaged in constructive play should be able to rearrange, modify, adjust, and improve their creations and not follow strict instructions or rules (Forman \& Hill, 1984). For example, a child who creates a tower by stacking wooden blocks and adjusts the dimensions of the tower as desired is said to be engaging in constructive play. In this study, constructive behaviours will be categorized as constructive play if child-directed constructive behaviours are observed and construction if adult-directed task-oriented behaviours are observed. This differentiation is in line with more recent research that makes a distinction between the two (Pellegrini, 2009).

Pretend play, also known as symbolic play or dramatic play, refers to children's play that involves some element of pretense (Smith, 2005). Smilansky and Shefatya (1990) classified the 
types of pretend play as either imitation from some personal experience (e.g., observed actions of parents) or imagination, which involves a richer make-believe context for the play episode. Sociodramatic play refers to pretend play involving one or more play partners (Smilansky \& Shefatya, 1990).

Games with rules, typically emerging as a play form between the ages of 4- to 7-years, involves "competitive inter-individual relationships in the context of regulations as to possibilities and prohibitions, with sanctions for violations” (DeVries, 2006, p.119). Kamii and DeVries (1980) categorized games according to purpose, such as aiming, racing, chasing, hiding, and guessing; or as games involving verbal commands, card games, and board games.

These four types of play have been shown to influence various areas of cognitive development in children. It is important to keep in mind that in very young children, what may look like object play, may actually be exploration. Exploring is seen as a crucial step in the development of play (Thorp, 2003). In this study, exploratory behaviour is defined as interacting with or exploring an object, rather than playing. The distinction is made based on careful observations of the child's actions: if the child acts in a deliberate manner by turning the object around to inspect all sides, touching the various surfaces of the object, listening carefully to sounds made by the object and so forth, these behaviours would be categorized as exploratory. Often these exploratory behaviours can be inferred from the child's serious and attentive facial expressions (Ruff \& Lawson, 1990). Once children feel confident about their knowledge of an object, they are ready to play and discover what they can do with it (Gopnik, Meltzer, \& Kuhl, 2001).

The aforementioned types of cognitive play observed in the early years occur within a variety of social contexts (Rubin, 2001) such as at school, in the playground, and at home to 
name but a few. Studies have shown the developmental significance of young children's early interactions and play within social settings (Rubin et al., 2005). These types of social play were most notably categorized in Parten's (1932) study. She identified six categories: four non-social (or semi-social) behaviours, which were unoccupied, onlooker, solitary, parallel; and two social play categories, associative and cooperative. Parten's (1932) observational framework of social participation continues to be used by researchers for the purposes of examining children's social and non-social behaviours (Coplan, Rubin, \& Findlay, 2006). Coplan, et al. (2006) highlighted Parten's definitions of these terms as described below.

Social Play. Unoccupied behaviour refers to a “marked absence of focus or intent” (p. 76). Staring blankly into space or wandering aimlessly are examples of unoccupied behaviour. Onlooker behaviour refers solely to the observation of others' activities without joining in on them. Solitary play refers to the behaviours of children who play within close proximity of others, while disregarding the presence of others. Parallel play refers to children who play next to one another (often with the same types of toys such as blocks) but independently, neither influencing nor modifying the play of the children around them. Associative play is considered socially interactive play as the child interacts with other children. There is explicit acknowledgement of others' activities and interests. Lastly, cooperative play is the highest level of socially interactive play as the children come together to carry out a plan or attain a goal. This includes play such as collectively acting out a dramatic scene or playing a formal game (Parten, 1932).

\section{Object Play in Young Children}

Observing cognitive and social play behaviours, which emerge at various stages during the first four years of life and beyond, researchers have learned a great deal about young 
children’s cognitive and social development (Garner \& Bergen, 2006). In the first years of life, these interactions and play experiences involve various play materials and other people, such as parents, caregivers, and other peers. The vast research on play with various objects has been shown to have an impact on each of the five domains of child development—physical, cognitive, social, emotional, and language development (Gaskins, Haight, \& Lancy, 2007; L’Abate, 2009). The following section will address the specific influence of play materials on children's cognitive and social development.

Cognitive Development. As infants become more mobile, they explore more of their environment, increasingly manipulating objects they encounter. These beginning steps of exploration set the tone for advanced developmental skills in many areas (Bergen, 1998). In very young infants, typically under the age of 7-months, indiscriminate mouthing or striking objects, food, and even people were common, while older infants began to differentiate their exploratory behaviours. For example, older infants tended to shake and rattle objects and playthings and mouth smaller objects but rarely mouthed people’s hands and fingers anymore. As infants enter their first year, oral exploration of objects diminishes and tactile and visual exploration increases (Mayes, Carter, \& Stubbe, 1993).

In another study on young infants’ object play, Baldwin, Markman, and Melartin (1993) established that patterns of exploratory behaviours emerged between 9- and 16-months, and infants were capable of making inferences about novel objects based on brief exposures to objects with similar appearances and properties. A key finding of this study is that the infants' behaviours were not due solely to the experimenter's demonstrations but as a result of the infants' inferential capabilities. In a more recent study by Needham, Barrett, and Peterman (2002), infants' attention to and exploration of objects were enhanced by prior experience, 
compared to their peers who had not received any play sessions with objects prior to testing. In addition to the increase in number of explorations, Needham et al. (2002) found that the infants with prior experience engaged in more complex object exploration strategies as well. Both studies highlight the importance of experience on young children’s cognitive abilities.

Further, in a cross-cultural study with American and Ivorian infants, DeLoache, Pierroutsakos, Uttal, Rosengren, and Gottlieb (1998) investigated behaviours of infants from two age groups when presented with symbolic objects - in this case, a picture book. The American infants were from a middle class family, and the Ivorian infants were from the Beng community, a largely impoverished rural community in the Ivory Coast in which printed pictures were uncommon. In both cultures, the young infants, who were roughly 9-months-old, showed similar manual exploratory behaviours when given the book with a realistic picture of an object. In both studies the objects would have been common in the particular child's culture. Although the testing conditions were markedly different in Ivory Coast than they were in the American laboratory setting, their findings suggest that both groups of children had yet to understand that the pictures in the books were symbolic. This was determined as the infants often attempted to grasp the object in the picture by extending their fingers toward the image and curling their fingers around it. On the other hand, the 19-month-old children showed few instances of trying to pick at the object on the page and instead pointed to the picture, often accompanied by vocalization that was directed toward an adult. DeLoache et al.’s (1998) study is significant in showing the progression of learning that happens from young children's initial explorations and subsequent interactions after many experiences have accumulated. In some areas of cognitive development, there is an understanding of progressive stages of learning and in this particular situation with very young children, the results were not influenced by culture. In another multi- 
national (i.e. India, Turkey, Guatemala, and the USA) cross-cultural study, Göncü, Mistry and Mosier (2000) found that a having limited toys decreased the number of interactions with objects during unrestricted playtime, but when introduced to novel play materials by caregivers, all children engaged in similar ways. As infants begin to understand that their actions and interactions have a purpose or an effect, simple exploratory behaviours will decrease and functional play will increase (Garner \& Bergen, 2006); however, novel objects continue to elicit the greatest amounts of exploration and attention (Willats, 1983).

As objects have been shown to impact infants’ cognitive development, the support for environments that provide various toys and objects is growing (Forbes, 2004). Unfortunately, this has fueled many in the toy industry to market infant and toddler toys as a necessity for healthy cognitive development. An interesting finding that supports the idea that play materials do not need to be expensive or elaborate and perhaps just the opposite was seen in Bartie et al.’s (2015) study with young children from a low socio-economic village in South Africa. When the children did not have all the necessary equipment for a certain game or had various random items, they made their own toys for play, using materials that were available to them in their environment (Bartie et al., 2015). The processes of gathering, organizing, creating, and representing are important cognitive skills that should be developed in early childhood.

This research is in line with some of the earlier studies on the impact of play materials on child development, namely Bloch’s (1984) study with young children in Senegal. Bloch (1984) also found that the scarcity of toys did not deter the children from engaging in object play. In fact, they occupied themselves in constructive play, which included everything from constructing simple cars and trucks out of empty tins and more elaborate houses for sociodramatic play. The materials that children gathered from their environment afforded a plethora of play activities, 
influencing many areas of development, including cognition. Her study showed that materials and objects for children's play and exploration do not need to be expensive or complex. In fact, a crucial component in toy quality is the level of affordance of the object (i.e. possible ways to use an object). In the conclusion of her study, Bloch posed very important questions regarding the effects of too many specifically designed play materials on children's ability to be imaginative and creative. In order to understand in what ways objects may influence creativity and inventiveness in children, Ness and Farenga (2016) analyzed the levels of affordance of certain objects (i.e. blocks, bricks, and planks). Over thirty years later the concern regarding affordance of objects is still a concern for researchers as there are increasingly more toys that claim to improve a child's cognitive development.

The simple objects used by the children in Bloch's (1984) study had many affordances, influencing various types of play. For instance, after the children had constructed something, they used what they had constructed in pretend play. There are various stages of pretend play, which first appears around 12-months of age and is often child-focused and solitary, but around 30 months of age, it can become more of a social activity (Howes, Unger, \& Seidner, 1989). Both Bartie et al. (2015) and Bloch (1984) observed that young children’s pretend play scenarios reflected their lived experiences and were influenced by their environment; thus, the children in Senegal and South Africa both engaged in pretend play that depicted scenarios and situations that may commonly exist in their real lives. The influence of the environment on pretend play is also observed in Western children who more frequently engage in fantasy pretend play (L'Abate, 2009) than their non-Western counterparts. This phenomenon may be a result of Western media influences. 
Cognitive development in early childhood involves various skills such as problem solving, representation, questioning, observing, sorting, organizing, reflecting, hypothesizing, and reaching conclusions (ELECT, 2007). As children's play develops and becomes more elaborate, their social skills during play also develop. In fact, in many Western and non-Western countries, young children are spending increasingly more time outside of their home and in child care programs where they are with other children similar in age. Therefore, it is important to discuss children's social development in the early years since all of these interactions can influence their development.

Social Development. For infants and toddlers, social play often includes playing together with an object and adult/peers. Young infants' first play partners are often their parents or primary caregivers. Research suggests that parent-child play interactions are especially important for later play and social development (Forbes, 2004; Garner \& Bergen, 2006). One study during the early months of infancy found that children's play needs should be matched by adult guidance, and due to this joint interaction, the child's play was more intricate and intellectually stimulating (Bigelow, Maclean, \& Protor, 2004). Decades earlier, Main (1983) found in her short-term longitudinal study of 40 infant-mother dyads that security of attachment at 12-months of age influenced 21-month-old children's exploratory behaviours, social behaviours, cognitive development, and language in that securely attached children were more social with playmates and engaged in longer and more attentive exploratory behaviours. With children leaving the care of their families at a very young age to attend child care programs, it is necessary to study children's attachment security with early childhood educators/caregivers at their child care program to see how that may affect a child's social development. 
As mentioned above, with more children being enrolled in child care programs in early infancy, many researchers have studied infant and toddler peer interactions in play settings (Deynoot-Schaub \& Riksen-Walraven, 2006). Positive peer interactions in infancy have been found to predict later social competence, even in infants who are one-year-old (Howes \& Phillipsen, 1998). Social engagement in children is characterized by very simple gestures such as imitation and smiling by infants to more complex functions such as resolving conflicts and empathizing in preschoolers (L’Abate, 2009). Williams, Ontai, and Mastergeorge’s (2010) findings also support this change in interaction with age, stating that under one year of age, infants will generally interact with peers by exploring one another's face and bodies while sitting close together, whereas children older than one year of age will begin to offer peers objects and study each other's interactions and activities. Eckerman and Whatley (1977) found that infants between 12- to 24-months of age who were in a room with their peers but without toys interacted more with one another: smiling at, gesturing at, touching, hitting, and imitating one another. When toys were available, the children interacted more synchronously with each other and the play material, showing each other their play materials and even exchanging them. Jacobson (1981) also found that children 14-months of age were involved in longer interactions with peers when objects were available for play, but this was not the case for children who were younger than 12-months of age. A study by Brownell, Ramani, and Zerwas (2006) also found that young toddlers would engage in collaborative behaviours when provided with the right objects. In their investigation, most 19-month-old toddlers had learned to work together to pull separate levers in order to get the object to play music. By 24-months of age, all participants were able to collaborate with peers on this task. This research emphasizes the importance of varied objects that may elicit different kinds of social play. 
Other recent studies on children's use of objects during social play present several interesting findings. First, open-ended materials or toys inspired high quality play, particularly constructive play and pretend play (Bartie et al., 2015; Hoyte, Degotardi, \& Torr, 2015; TrawickSmith, Russell, \& Swaminathan, 2010). For instance, Trawick-Smith, Wolff, Koschel and Vallarelli (2015) found that open-ended toys such as Duplo ${ }^{\mathrm{TM}}$ bricks and Rainbow ${ }^{\mathrm{TM}}$ people resulted in more creative play, mainly as pretend play props, by the children. Elaborate pretend play amongst young children is one of the main indicators of social skill development. However, as mentioned earlier, certain toys elicit different play behaviours and a toy that elicits solitary play and not social play is not necessarily "low-quality”, but instead must be understood in the context of the play (L'Abate, 2009).

Current research has investigated the benefits of low-cost, readily available play materials for children’s play and has found many collaborative, imaginative, and social pretend play incidents from children using such materials (Bundy et al., 2009). However, a more recent study showed that the same toys were used differently based on gender, ethnicity, and socioeconomic status, lending credibility to the claim that culture and the environment influence the toy play of preschool children (Trawick-Smith, Wolff, Koschel, \& Vallarelli, 2015).

Given very basic play materials, which comprised of pebbles, pegs, bottle tops, small colourful building blocks, etc., children's choice of play topics was influenced by the quality of peer relationships and the duration of play (Hoyte, Degotardi, \& Torr, 2015). In addition, Howes (2011) found that positive play experiences may contribute to the growing sense of friendships. Similarly, Nwankwo (2015) investigated the relationship of play materials on the development of social skills in Nigerian children, focusing on interactive skills, sharing ability, leadership skills, and competition. Findings concluded that a significant positive relationship exists between play 
materials and the development of social skills (Nwankwo, 2015). However, Nwankwo's methodology of administering a four-point Likert scale questionnaire to preschool children after a two-day intervention raised concerns regarding the validity of the findings. This rating scale may not be effective with young children as they are more likely to think in extreme terms (Chambers \& Johnston, 2002).

\section{Gap in the Literature}

The vast research on young children’s early cognitive and social play predominantly constitutes findings from Western cultures, often with older preschoolers and in experimental contexts, which were highly controlled and not naturalistic. Play in young children from Nigeria has rarely been studied. This is no surprise as play—particularly object play—in young Nigerian children has only recently been emphasized as a critical component for children's development (Ige, 2011). The literature emphasizes the importance of gaining a better understanding of young children’s play in various cultures (Göncü et al, 2000; Trawick-Smith, 2010). Sutton-Smith (1979) supported this notion, claiming that object play is "mediated through social interactions and social traditions” (p. 8), which are critical in determining the extent and the nature of children's play. There is some cross-cultural evidence of play behaviours (cite all the studies here, including Göncü, the Senegal study, etc.) but these studies have typically looked at the role of others engaged in the play, and not simply at the reactions of infants and toddlers to novel play materials. Thus, studying young Nigerian children’s reactions to novel play materials, without the influence of another adult or caregiver in a natural setting will add to the play literature of children from non-Western cultures. This is especially relevant as studies continue to show that play is paramount in enhancing cognitive and social development. Thus, the current study addressed the issue of the limited research on children’s play in Nigeria by investigating 
young Nigerian children, living in Abuja, Nigeria and attending a private crèche, as they engaged with novel play materials. This study is significant in that it explores, for the first time, young Nigerian children’s cognitive and social play with novel play materials at their crèche.

\section{Theoretical Framework}

The role of objects in shaping children's development has been debated from a variety of theoretical perspectives. As this study looked at both cognitive and social play with respect to object play, two theoretical viewpoints were taken: the developmental/cognitive view and the social play theory. The developmental/cognitive perspective sees play with objects as the way in which cognitive functioning is developed and improved (Piaget, 1962). More specifically, cognitive play theory focuses on the development and enrichment of reasoning and problemsolving strategies that arise through playing with various objects and materials. As this present study was conducted in a social setting (a crèche), Parten's (1932) theory of social play will provide a framework for the analysis of social participation between and among the children during the introduction of play materials. The benefit of Parten's categories of social participation is that despite the methodological changes since her original study, the taxonomy provided by Parten is workable in many areas related to children's social and nonsocial play (Coplan et al., 2006). Each theoretical view of play with objects attaches different types of meanings to children's play, and one must have an understanding of the child's behaviours and the context of the play in order to make inferences regarding a child's development (Morgenthaler, 2006). Thus, integrating these two long-standing play theories—cognitive play (Piaget, 1962; Smilansky, 1968) and social play (Parten, 1932)—generated the conceptual framework, which also served as the coding scheme for data analysis. The details will be discussed in the next chapter: Methods. 


\section{Chapter 2: Methods}

The opportunity to conduct research in Nigeria was made possible due to the collaboration among a not-for-profit Canadian organization, a Canadian university, the Nigerian government, UNICEF Nigeria, and other educational institutions in Nigeria. This particular notfor-profit organization has been working closely with the Nigerian Ministry of Education and UNICEF Nigeria to bring play-based learning to Nigeria. Thus, the larger project focused on documenting a pilot intervention on play-based education in a primary school and a child care program in Abuja, Nigeria. For this larger project, I was a participant-observer, along with three other students (one undergraduate and two Master of Arts students). I interacted, engaged, and played with the children and documented observations during this intervention.

In addition to my role in the intervention, as a Master of Arts (MA) student, completing a Major Research Paper, I planned to conduct an independent study. As the intervention focused on play-based education, I hoped to gain some insight into children's perceptions of play in their child care programs. There is limited literature on young Nigerian children's play; therefore, understanding children's views on play would be beneficial in supporting educators and caregivers as well as inform play-based learning curricula in Nigeria.

Through semi-structured and conversational interviews, via child-led tours and child-led play (Johnson, Hart, \& Colwell, 2014), the aim of my original study was to collect data with children regarding their perceptions of play in their child care program. However, on the first day I discovered that most of the children enrolled at the 'crèche,' a place where young children are cared for during the work day, were infants and young toddlers, and thus many were pre-verbal and pre-locomotive. Although the crèche is open to children between the ages of 4-months to 36months, the average age of the children at the time of the study was approximately 12-months. 
Therefore, documenting children’s perceptions and preferences regarding play was not possible. In addition, as the crèche was more of a caregiving environment with little to no emphasis on play, the children did not have toys or materials available to play with freely, which also affected the design of the original study. Consequently, the original study was not carried out as planned.

Despite the lack of toys, however, play did occur among the children, particularly social play behaviours. For example, initial observations on the first and second day at the crèche showed that children played with objects such as one another's socks and shoes as well as with the baby walker and the infant rocker chair. The children also played together by following one another around the room and engaged in physical contact such as hugging, pulling one another's clothes, and so forth. The observations made regarding the children's play at the crèche without traditional toys presented a unique opportunity to investigate the children's interactions when novel play materials are introduced.

\section{The Present Study}

As is the nature of field-based research (Hatch, 2007), the study was modified to accommodate the discoveries that arose on the first day. Fortunately, the undergraduate student from Canada was also working on a project for her international placement, which was a requirement of her university program. She was responsible for making or gathering play materials for the children over the course of the four-week course. In keeping with my original plan to study children's play, I decided instead to observe the children's engagement with novel play materials. These novel play materials were introduced in collaboration with the undergraduate student and the overall approach to design (using local materials, for example) and slow integration of materials (discussed below) were based on the methods used by the nonprofit organization over the past several years in development work in early childhood education 
(approach discussed in more detail, below). As the student interacted with the children, she was also considered a participant in the study. In order to gain insight into the cognitive and social development that occurs through children's play, the following questions were asked: (1) How do children interact with novel play materials that are introduced to them at their crèche? and (2) What types of social play occur when the children are introduced to these materials?

\section{Research Design}

According to Hammersley (2014), observations by researchers can be carried out in two ways: detached and participatory. In this study, data were collected using both participant observations and detached observations, via running record note-taking and video-recordings. Participation observation was an effective approach for this study as I was already interacting with the children. If a child approached an adult (i.e. caregivers, the other student from Canada, or myself) with a play object and initiated play, the adult would engage in play with the child. If this occurred during the introduction of the novel play materials, either the other student or I would video record the interaction. Detached observations occurred when children did not interact with adults, but engaged with the novel materials on their own.

\section{Setting}

The study was conducted in a crèche located in Abuja, Nigeria. The crèche is located on the ground floor of a large government building in the city’s financial/government district. This location was one of two made available to us for the larger study, and it is run by the host government agency. The two caregivers who work at this crèche are not formally trained early childhood educators, but they did receive workshop training for a half-day by the lead of the larger study, and they also acted as collaborators in the design of play materials. 
This crèche consists of one large room that is divided into four general areas (see Appendix A for Figure 1 for the crèche floorplan). In one corner there is a dining area with childsized furniture (e.g., table, chairs). Children bring food from home and the caregivers feed them within this dining area. Along one wall there are windows—changing pads are placed along the window sills. Along the wall, opposite the windows, there are cubbies for the children's belongings and a small child-sized table. There are two twin mattresses on the floor for sleeping. In the centre of the room there is a small carpeted area, which is the children's designated play area. The crèche had only one toy available—a plastic activity gym, typically used by infants.

\section{Participant Demographics}

The participants were chosen from a purposive sample from a multi-age (birth to 35 months) crèche in Abuja, Nigeria. From a group of 12 children, 10 children participated in the study. The group consisted of children between the ages of 7- and 24-months of age. All the children were Nigerian, but from diverse ethnic backgrounds such as Igbo, Hausa, and Yoruba to name a few. Although the caregivers occasionally addressed the children in their regional languages, the caregivers usually spoke to the children in English, which is Nigeria's official language. Children between birth to 17-months-old and 18- to 35-months-old were considered infants and toddlers, respectively. One 3-year-old did not participate in the study as he only attended the after school program and not the regular day program. One 18-month-old did not participate in the study as she joined the program during the last week of data collection. A 3month-old child and a 6-month-old child had parental consent to participate in the study but were not included in the analysis, as they did not appear in any of the video recordings. In this particular program, the families served by the crèche are largely civil servants or professionals who work an 8:00 am to 4:00 pm schedule, and are therefore best described as middle class. As 
the federal capital city, Abuja is home to many Nigerians from different regions across the country as well as to many expatriates, making it a multi-cultural city with a heterogeneous population.

As a researcher, I was a participant-observer in this study. The two female caregivers and the two students from Canada were also participants of the study, as they were often involved in the children's play, either by playing with them directly or by helping them indirectly (e.g., giving them materials). The two students from Canada acted as videographers in the event that I was participating in the play with the children.

\section{Ethics}

When conducting research with children, there are numerous factors to consider. This section will be arranged into two categories: ethical treatment of participants and formal documentations. First, the participants’ rights, needs and values were respected (Creswell, 2013). One of the most important aspects of the study was to ensure that the children felt comfortable with our being in their play area and that the play materials we introduced did not pose any safety hazards. The children could choose to engage with the play materials at their discretion. When a child asked me to play, I gave the child my full attention and did not put data collection before my interaction with the child (Bucknall, 2014).

As a researcher who was also an outsider (not from the same culture as the study's participants), I also had to consider the existing power relations created between myself and both the children and caregivers at the crèche. Although I was conducting research, I made an effort to minimize the disruption in the overall flow of the program. It was important for me to ensure the program ran as it normally would, with the caregivers leading and running the day-to-day activities. In fact, I entered this crèche as a researcher but also as a learner. As a learner in this 
environment, I followed the lead of the caregivers and interacted with the children as the caregivers would. I found it was best to find a balance between my role as a caregiving adult as well as a researcher-adult. Therefore, when playing with the children, I took a 'curious adult' role (Best, 2007). Adults have the power to influence children's values, attitudes and behaviours (Santer \& Griffiths, 2007). By taking a curious adult role, I was able to observe the children's play and engagement without guiding or showing them.

As the children had not participated in a research study before, parents raised several concerns regarding the data collection. These concerns were identified both informally through the consent process (conversations with parents), as well as through formal focus groups that were part of the larger project, and not part of the current study. Parents were informed that data were to be collected using video recordings, and the videos were shown to the parents following the study to ensure that they felt that the data were representative of their children's time at the crèche. Parents were assured that the videos would not be shown to others beyond the purposes of the project. Signed consent was obtained from all the parents. Written or oral assent was not obtained from the children since they were too young. Pseudonyms were given to the children during the coding process to protect their identities.

\section{Materials}

Aside from a few supplies (i.e. laminating tape, crayons, and children’s picture books) play materials used for this study were purchased or gathered in Nigeria. Play materials for the study were chosen based on the guidelines from the Early Childhood Development (ECD) Trainers Guide (ECDI, 2016), a guidebook created by the non-profit organization leading the larger project to provide training for early childhood educators in Nigeria. The guidebook emphasizes finding materials in the home and the local community that will engage the children. 
Features such as colour, utility, and safety were considered when choosing materials for children. The materials were also chosen based on stimulating different types of play. Table 1 lists the play materials that were introduced in this study, the day the play materials were introduced, and by whom they were introduced. On Day 1 and 2, new play materials were not introduced; rather the children's regular play at their crèche was observed (see Appendix B for Table 1).

\section{Procedure}

As mentioned above, data were collected through detached observations and participant observations for 16 nonconsecutive days within a four-week period. Both types of observations were used at various times throughout the study. Data were collected at various points, in line with the emergent nature of the study. Running records were only taken during the initial observations on days 1 and 2, before the introduction of play materials; therefore, only the data from video-recordings were analyzed for the purposes of this study.

Video-recording. Researchers have shown many benefits to using video to record observations (Graue \& Walsh, 1998; Hancock, Gillen, \& Pinto, 2010; Walsh et al., 2007). For one, videos allow for "the opportunity to amass rich, detailed documentation of the children's interactions in their everyday environments” (Gillen \& Cameron, 2010). Bronfrenbrenner (1979) also stated that through close and repeated observations, one is able to identify aspects of a young child's life that at first glance may seem incidental. Video recordings allow for these repeated and close observations.

The first two days of the study were dedicated to establishing relationships with the children and the caregivers. According to Johnson, Hart and Colwell (2014), building relationships with the children is crucial for two fundamental reasons: (1) children must be treated with respect and their safety must be prioritized, and (2) a trustful relationship is required 
to create a safe and enjoyable environment for the children. In concordance with Johnson et al. (2014), the children's comfort and safety were of utmost importance during this study. For two twenty-minute periods on the first two days, video recordings were taken of the children during their naturalistic play. One of the main reasons for this was to expose the children to the video recorder, a compact handheld digital video recorder. A few children were curious and requested to see the video recorder. I showed the video recorder to the children and explained that it was not a toy. After the first day, they did not ask to see it again. It is unreasonable to think the children did not notice the video recorder, however, and it is evident in some recordings that the children are aware they are being recorded. Despite this awareness, the children did not show any uneasiness or displeasure and went about their play without much regard for our presence or the presence of the video recorder. Other researchers who collected video data with children in the field, including Walsh et al. (2007) and Gillen and Cameron (2010) made similar observations.

Introduction of novel play materials. Each novel play material was introduced separately, either by the caregivers or myself. As mentioned earlier, the play materials were chosen or created in advance in a collaborative effort between the caregivers and us (the students from Canada). Whenever possible the caregivers were the ones to introduce the play materials to the children. The process by which materials are presented to children can influence how they engage and interact with them (Strong-Wilson \& Ellis, 2007). The presentation of play materials followed a method that was similar to that of the Reggio Emilia approach, called provocation. The Reggio Emilia approach is an educational philosophy based on the image of the child who possesses strong potential for development, which is enhanced by the child's relationship with the environment and others (Edward, Gandini, \& Forman, 2011). Provocations ensure that items 
are presented in a child's environment in a way that provokes a sense of curiosity and inquiry (Fraser \& Gestwicki, 2002). Therefore, in this study, following the principle of provocation, the play materials were placed in the middle of the children's play area or on the table along the wall. No instructions were given to the children regarding the usage of the play material; instead the children engaged with the materials however they pleased. In this way our roles were less as participants, and less prominent—it is here where I was an observer and the children chose how they wished to interact with the objects. When the play materials were introduced, the children could invite adults into their play if they wanted. Using a strategy proposed by Corsaro (1985), the strategy for this type of interaction was to let the children invite me into their play and to follow their lead. The play materials were put away at the discretion of the caregivers, depending on their plans for the day. On some days more than one play material was introduced but never at the same time. An exception to the presentation of the play materials was with the picture book, which was read to the children by the caregiver as she sat in the middle of the room.

Video-recordings started when the play materials were placed in the centre of the play area until the children stopped playing. A child was deemed "ending play” if they purposefully put down the play material or stopped engaging in play behaviours with the object or others. We also discontinued the recordings if the caregivers called or took the children away from their play in order to feed them or change their diapers and/or clothes. The general rule for video recording was to record as much of the play area and keep as many of the children in the frame as possible, although this was difficult at times as the children would often remove the play materials from the carpeted play area. In these cases, we followed the children as long as their play was a continuation of the same play episode. In this study, a play episode is defined as a single event in which one or more children are engaging with the novel play materials and/or each other. 
As frequently as possible, field notes were written during the data collection period to give more details and context to the videos taken. In some cases these field notes were taken immediately after the videos were recorded and in other cases the field notes were taken at the end of the day. As noted by Hatch (2007) and Graue and Walsh (1998), field notes are needed to contextualize video since the meaning behind a recorded action may not be as obvious after the fact. The field notes were not analyzed, but were used to give context when needed.

\section{Data Analysis}

Parsing Video Data. In all, 38 videos were recorded, totaling 136.7 minutes of film. Only the videos documenting the initial contact with the novel play materials were included in this study. The total time for these videos is 64.25 minutes. All subsequent videos and videos of integrated play materials were excluded. Ten novel play materials were introduced (see Table 1) and eleven videos were analyzed. The eleventh video was a continuation of the video for the introduction of plastic fruit toys (Day 10), which was accidentally stopped prematurely by the researcher before the play episode had finished. The second half of that video was taken within seconds of the first one and ensured that the play episode was intact.

Logging Video Data and Constructing a Data Record. Data were logged and data records were made using a specialized data record table created for the purposes of this study (see Appendix C for Figure 2). Following the steps outlined in Graue and Walsh’s (1998) chapter on constructing a data record, each of the eleven videos were logged and time stamped according to the start and end time of each play episode. The number of play episodes varied per video and in some videos the play episodes overlapped with one another; thus it was important to time stamp and categorize each separate play episode. 
Once all the play episodes were logged, each play episode was reviewed multiple times to create a detailed description of the behaviours observed. The play episodes were transcribed using a running record strategy to document every action of the focal child(ren). Video recorded behaviours and actions were constructed into a data record before they were analyzed (Graue \& Walsh, 1998).

Bias and error. Graue and Walsh believe bias can be introduced during any step of research and data collection is no exception (1998). As a researcher I acknowledge the reality of biasing my data record. As confident as I am with my descriptions in the data record, I am aware of the data record being influenced by my present beliefs and attitudes. In an effort to minimize this bias, any uncertainties regarding a child's behaviours were corroborated with field notes that were taken during the time of the video recording.

Conceptual Framework and Coding. The conceptual framework for this study was influenced by two long-standing play theories: cognitive play (Piaget, 1962; Smilansky, 1968) and social play (Parten, 1932). Specifically, the conceptual framework that guided the design and analysis of this study incorporates the cognitive forms of play as they occur in a social contextin this case, a crèche. Rubin's (2001) play observation scale is one instrument that allows for children's cognitive and social play behaviours to be analyzed together. This scale was modified to suit the needs of the current study. First, I coded the children's behaviours with the novel materials as either non-play (i.e. exploration) or play (i.e. functional, constructive, or pretend).

Exploration was defined as an investigative action whereby knowledge of the material or object is gained (Collard, 1979) and is described in detail in Chapter 1. Functional play referred to object play in which the child acts on or does something to or with an item, simply for the enjoyment it brings (Rubin, 2001). Constructive play was indicated by a child's voluntarily 
creating or constructing something, both physical and abstract (Forman, 2006). Pretend play referred to children's play that involves some element of pretense (Smith, 2005). Non-play construction was differentiated from constructive play if the behaviour seemed more adultdirected and less intrinsically motivated by the child (Forman \& Hill, 1984). Games with rules was not considered in this study due to the age of the participants (DeVries, 2006).

Next, the children’s social behaviours were categorized according to Parten’s (1932) social play definitions. As the study focused on engagement with novel play materials, social play behaviours that did not involve the objects were not analyzed. Therefore, the categories used were onlooker behaviour, solitary play and parallel play. Onlooker behaviour was indicated if the child observed others' object play but did not join in. Solitary play referred to children’s independent play, with little or no acknowledgement of those around them. Parallel play referred to children's play that was independent, but within close proximity of other children so their

presence was recognized. Associative play and cooperative play categories were not reflected in this study due to the age of the children (Parten, 1932). This conceptual framework drove the categorization of behaviours based on these two play hierarchies and resulted in eight possible nested behaviours (see Appendix D for Figure 3 for the object play coding scheme).

\section{Trustworthiness}

In order to maintain the validity of the data, several measures were taken. First, to familiarize myself with the children and to minimize reactivity, I spent the first two days getting to know the children and ensuring an ease and comfort during my interactions with them. Establishing a relationship with the caregivers was another way to build trust with the children; they were more likely to open up to me when they could see that their caregivers were accepting of me. For nearly four weeks, I arrived at the crèche at 8:00 a.m. and left at 2:00 p.m., spending 
my time playing with and caring for the children and interacting with the caregivers. In total, I spent 80 hours at the crèche.

In addition, qualitative reliability ensures that the researcher's approach is an appropriate method to study the topic on hand (Creswell, 2013). All data collected were reviewed and a strict guideline was followed to parse the data. I found concordance between data from the videos and information written in field notes, which gave credibility to the construction of the data record. Finally, I checked the transcripts for errors in wording to ensure consistency among videos and the codes for exactness of descriptions to ensure accurate analysis of observed behaviours. 


\section{Chapter 3: Findings}

The purpose of this study was to explore young Nigerian children's play with novel play materials that were introduced to them at their crèche. The study was conducted over a fourweek period, in which eleven novel play materials were introduced to the children (see Table 1 for a detailed list of play materials and when they were introduced). Participants were eight children between 7- to 24-months of age.

This chapter presents the findings as they pertain to the two research questions for this study: (1) How do children engage or play with novel play materials in their crèche?, and (2) What types of social play were observed during the children's play with these novel play materials? Both questions were simultaneously analyzed using pre-established codes based on the conceptual framework presented in chapter three. The following section will discuss the ways in which children played with the novel play materials. The findings will be presented according to the cognitive play categories. Social play categories are highlighted within the cognitive play categories (see Appendix E for Table 2 for the frequencies of coded behaviours). A short summary will follow to conclude the chapter.

\section{General Findings}

Over the course of four weeks, 11 novel play materials were introduced to the children at the crèche. These items included the following: empty plastic water bottles filled with various materials such as seeds, oil, leaves, cotton balls, corn kernels; a children's picture book; disposable red plastic cups; small jam jars with lids; a large wooden 'treasure’ bowl filled with various items such as small containers, wooden bangles, a small wooden bowl, an African hand drum, a small dried gourd, handmade cardboard boxes, a wooden bristle brush, etc.; a sheer 
orange sheet of fabric; drawing paper and crayons; plastic fruit toys; homemade playdough; and a plastic nesting cup set with 8 cups.

In total, 29 play episodes were observed. Of the eight possible nested behaviours that were anticipated, six types were observed. Parallel-constructive play and parallel-pretend play behaviours were not observed during the play episodes. In addition, six of the total 29 play episodes did not fall under any of the nested categories. These play episodes were separated into two groups: (1) adult-led group reading activity, and (2) simple social play. Actions unrelated to the children's play with the play materials or other people were not analyzed (e.g., stumbling, bumping into something, dropping something accidentally). Actions such as moving/walking towards and picking up/grabbing novel play materials were observed during the introduction of every play material with the exception of the picture book, which was the only item that the children did not engage with freely, as the caregiver was reading it to them.

\section{Exploration}

Exploration was seen in 12 of the 29 play episodes. Six of these were solitary-exploration behaviours. In one case, Brandon, a 7-month old boy, picked up a disposable plastic cup and immediately put it in his mouth, sucking and biting it. In another play episode, he explored the properties of a small wooden bowl by striking it against another object as well as putting it in his mouth. Zoey and Kyle, both 12-months-old, showed solitary-exploration behaviours during the introduction of the shakers (plastic water bottles filled with seeds, corn kernels, etc.). The shaker elicited extensive exploratory behaviours in both children as they shook, examined, and mouthed the shaker. Kyle spent several minutes exploring the shaker:

Kyle shakes the shaker with seeds close to his ear. He taps the shaker on the floor several times and then tilts the shaker upside down and right-side up, inspecting the seeds inside. 
Once again he strikes the shaker on the floor and even rolls the shaker several feet across the floor. As soon as he picks up the shaker, he puts the lid of the bottle in his mouth for a brief moment before shaking the shaker with both hands. He then proceeds to bang the shaker on his leg, examining the seeds inside closely afterwards. After repeatedly banging the shaker on his own body and the floor, he puts the lid end back in his mouth and tilts the bottle upwards as if to pour the seeds into his mouth. After several minutes of this exploration, he shakes the shaker aggressively with both hands.

Kyle was also observed in solitary-exploration behaviours in two other situations. In both play episodes he was putting the new objects (i.e. a plastic cup, wooden bangles, and a small wooden lid) in his mouth, chewing and sucking on the items.

Parallel-exploration was observed on six occasions: during the introduction of the sheer scarf and the playdough. The sheer scarf was draped over a string that was tied from a bar at the top of the window to a nail on the adjacent wall (like a clothes line). Brandon, 7-months-old, crawled over to the fabric and proceeded to suck on a small corner of it. He took the fabric out his mouth for a brief moment to look around the room, but then continued to suck on the fabric. In another example, Isaac, 18-months-old, was seen pulling on the sheer scarf, which made it longer on one side, almost dragging on the floor:

Isaac approaches the hanging scarf and gently tugs on one side. This causes the scarf to become slightly longer and drags on the floor. He then walks through it, letting the scarf glide against his face. After a few seconds, he gently tugs on the scarf again. He looks to the video recorder and to others around the room. Once again, he gently pulls on the hanging scarf. 
This behaviour indicated exploration as he inspected the properties of the scarf, both with his hands, as he actively moved the scarf along the string, and with his face, as he slowly walks through the scarf face-first.

When the playdough was introduced, many of the children made their way to the table to see it. Isaac, 18-months-old, made several attempts to touch the balls of playdough, but quickly retracted his hand every time, often shaking or rubbing his fingers on his clothing. He even moved to the other side of the table to try and touch another ball of playdough, but his reactions were the same- - he quickly pulled back his hand. He soon found a small patch of playdough stuck to the table and rubbed it with the tip of his finger. He did not withdraw his hand as quickly and continued to touch this small piece of playdough. Isaac was observed exploring the playdough, first by attempting to grasp a ball of playdough but eventually restricting his exploration to a small piece of playdough that he could rub with his finger.

Another interesting example of parallel-exploration was seen between Farah and Chantel, who are 18- and 14-months-old, respectively:

Farah picks up a small ball of playdough from the table. Chantel is standing next to her, looking at Farah and the playdough. Farah simultaneously mushes the warm ball of freshly made playdough between her fingers and inspects it. She then takes the ball of playdough and gently mushes it on Chantel's nose. Chantel looks a bit surprised, and Farah strokes Chantel softly under the chin as if to soothe her. Farah then walks away from the table with her ball of playdough, tasting the playdough as she walks. Although Chantel was standing at the table with the playdough, she did not immediately reach out to touch it. She did, however, make her way over to the table when the playdough was placed 
there by the caregiver, which indicates exploratory inquiry. She was examining the playdough visually.

In another play episode with the playdough, Dwight, a 10-month-old boy, crawled toward the playdough table, pulled himself up to a standing position and looked at the small balls of playdough that were placed on the table. Slowly he started to pick at one of the balls of playdough and inspected the little pieces. Then he dropped the little pieces of playdough on the floor or rubbed it on the table. He repeated this action several times. This deliberate behaviour of examining the material indicated that he was investigating the physical property of the playdough rather than playing with it; therefore, this action was considered exploration.

\section{Functional Play}

Functional play was observed in 5 of the 29 play episodes. Solitary-functional play was observed in two of the five episodes. In one play episode, Kyle, 12-months-old, was seen placing a plastic cabbage toy on top of a basket and lifting the basket. This action caused the plastic cabbage to roll off the basket and onto the ground. He was seen repeating this behaviour several times. The other solitary-functional play episode occurred when the paper and tray of crayons were placed on the table. Tia began rubbing the crayon back and forth along the paper. This behaviour indicated functional play and not constructive play as there was no indication of creating or constructing (e.g., drawing a picture); rather she aggressively made a few coloured streaks on the paper and then became more interested in collecting the crayons. She began to gather the crayons in her hand, first taking a couple and then grabbing a fist full. She walked toward me, showed me the crayons in her hand, and then took the crayons to another part of the room. The caregivers immediately told her to take them back to the table. Although she showed me the crayons, she did not give them to me nor did she initiate play. In this case, this play was 
considered solitary as the main interaction involving the paper and crayons was indicative of solitary-functional play.

Parallel-functional play was observed during the introduction of the sheer scarf and the treasure bowl. As soon as the scarf was draped over the string, Kyle, 12-months-old, immediately, but slowly, approached it. He first put his face gently against the scarf and then proceeded to walk through it. Once he got to the other side, he walked through it again, facefirst, and then went to go look at some pictures that were on the wall. After a few seconds, he came back to the scarf and very slowly pressed his face against it and walked carefully through. This behaviour indicated functional play as Kyle repeatedly walked through the sheer scarf in a manner that showed he was acting on the scarf in order to produce a specific feeling. The other two parallel-functional play behaviours were seen during the introduction of the treasure bowl that was filled with various items. Tia, 24-months-old, repeatedly struck the African hand drum on the ground, while Chantel, 14-months-old, rubbed her fingers along the prickly teeth of a bristle brush. In both situations, there was a lack of deliberate attention or focus on the object; in fact, both children were looking around the room at the other children and at the caregivers. The children were engaged in actions that resulted in physical sensations, typical of functional play behaviours.

\section{Pretend Play}

Pretend play was observed in 3 of the 29 play episodes. All of these were solitary-pretend play episodes. In one example, Tia, 24-months-old, was introduced to the plastic water bottles that were filled with water and oil.

With the bottle under her arm, Tia begins to separate my hair into several thin strands. [I am sitting in the centre of the carpeted play area.] She then takes the bottle and slowly 
tilts the tip of the bottle onto my hair, as if she is pouring the contents of the bottle onto my hair. She then gently rubs the strands of hair between her fingertips. After a few seconds, she repeats this 'pouring' and rubbing action on the strands of hair. After nearly a minute of this, she pulls the hair over my face, carefully rearranging the strands. She puts a strand of hair to one side and then to the other, each time inspecting how it looks on my head.

Although I was involved in this play, it was deemed solitary play, as she interacted with me as she would a prop or doll.

Kyle, 12-months-old, was involved in the other two examples of solitary-pretend play. In the first play episode, he put a red disposable plastic cup in his mouth and then tilted the cup upwards. He then peered inside the cup. Although brief, Kyle was engaged in a simple form of pretend play, as he was making a motion to drink from an empty cup. In the other play episode, his pretend play was more overt and obvious. Kyle was playing with plastic fruit toys. He held a plastic eggplant against his head, from his ear to his mouth, and yelled, "baaaaaa” into the fruit. He was babbling into the piece of fruit as he paced around the room. When the caregiver, who was feeding another child at the dining table, saw him, she called out his nickname, "Baba? Baba?” When he heard her call his name, he smiled widely and responded with another "baaaaa baaaa.” It seemed that the caregiver noticed he was pretending to use a phone, so she engaged in a conversation with him. He kept this eggplant toy against his head for over 30 seconds, nodding and babbling into it. This play behaviour indicated pretend play, as the child was using the fruit toy as if it were a telephone. Although the caregiver eventually joined in on the play, the initial interaction with Kyle and the toy indicated solitary-pretend play. 


\section{Constructive Play}

Solitary-constructive play was observed in 3 of the 29 play episodes. First, Zoey, 12months-old, was seen attempting to put a lid on a jam jar. She repeatedly pressed the two pieces together in her hand and even struck the pieces together on the floor in an effort to join them together. She repositioned the pieces in her hand many times and even sat down to regain her balance. Her actions indicated a serious determination to join the jar and the lid together. In a similar simple construction observation, Kyle, 12-months-old, held two red plastic disposable cups in his hand as he walked around the room. He attempted to put the wider (open) end of one cup into the other cup. After several tries to nest the cups, he extended the cups to the caregiver. Instead of letting her take the cups, he tried several more times but to no avail. In another solitary-constructive play episode, Tia, 24-months-old, played with 8 plastic nesting/stacking cups.

Tia has five plastic cups nested in one stack. She puts this stack of cups on top of a lone cup. The stack of cups doesn't nest into the lone cup, as the biggest cup in the stack is much larger than the lone cup. She removes the two smaller nested cups that are inside the stack and puts them inside the lone cup on the floor. She then takes another cup out from the original stack and puts the newly made stack in it. She repeats the process again with the following cup from the original stack, stacking the remaining cup. Believing she's stacked all the cups, she picks up the stack and proceeds to stand up. As she is standing up, she notices two overturned cups resting in front of her. She turns over the larger of the two cups and places it on the stack she has created. It does not fit. She turns over the other cup and puts it inside the previous one. She removes the two smallest cups 
from the larger stack and fills in the space with the newer cups she has found.

Successfully stacking all the cups from smallest to largest.

In all three play episodes, the children had intrinsically driven goals in mind and this behaviour indicated a form of simple construction.

\section{Other}

Two of the study's findings could not be categorized under the given nested behaviours, and thus, were analyzed separately.

Adult-led group reading. The children's introduction to the picture book was conducted differently than the other play episodes. Since the caregiver was reading the book to the children, they had limited access to it. The caregiver sat in the middle of the carpeted floor and five children were gathered around her. The children were between 12 -months to 24-months old. The two oldest girls in the group, 18- and 24-months-old, were the only ones who physically turned the pages of the book. In fact, the caregiver was still talking to the children about the pictures on one page, but the two older girls were eager to get to the following pages of the book, often tugging on the book. The caregiver momentarily engaged with the children who were tugging on the book and then continued reading to the group. The two younger girls, 12- and 14-months, sat and watched the caregiver point to and identify the pictures. Kyle, 12-months, left the group shortly after the caregiver started the story and began to climb a walker in the middle of the room. He would glance over at the group but did not remain seated with them.

Simple social play. Simple social play behaviours were seen in five of the play episodes and all of these play episodes involved the red disposable plastic cups. All five play episodes included the same three children: Tia, Zoey, and Kyle. In four of these play episodes, the children were stacking and collecting the cups. The children gathered the cups off the floor and 
stacked them inside ones they were already holding. In some cases, they would take cups out of their playmates' hands and add these cups to their collection. Although the child would become upset that someone took their cup, more often than not, the child would just collect another cup off the ground or take one from another child.

Kyle, 12-months, approaches the other children, holding a cup in each hand. He tries to stack one of his cups into a cup that Zoey, 12-months, is holding, but it falls on the floor. Zoey quickly picks it up. Kyle then hits one of Zoey’s cup with his cup and they both fall to the floor. He picks one up, while she picks up the other. He goes to stand up, but applies his weight on the plastic cups; they crinkle a bit under the pressure. He then tries to put the wider end of one cup into the other cup, but it won't fit. Tia, 24-months, comes over and takes one of Kyle's crushed cups out of his hand and walks away.

In another example of simple social play, Zoey, Kyle, and Tia were walking around the room with the cups in their hands. They walked over to the dining table in the corner. Zoey began to strike her cup on the chair by the dining table and Tia imitated her. Tia then took Zoey’s cup out of her hand, but Zoey continued to bang her hand on the chair, as she looked around the room. Kyle could not find space on the chair to bang his cup, so he moved over to a near-by the table and began striking his cup on the tabletop instead.

\section{Conclusion}

Children at the crèche interacted and played with the novel materials in all of the predicted ways, except for parallel-constructive play and parallel-pretend play. Overall, the most common behaviour observed was exploration and the most common social play type observed was solitary. However, there were just as many solitary-exploration behaviours as there were parallel-exploration. The most common type of cognitive play observed was functional play. 
Pretend play and constructive play were also observed, but only as solitary play episodes. In addition, two previously uncategorized findings arose: simple social play behaviours and behaviours associated with the adult-led group reading activity. 


\section{Chapter 4: Discussion}

The objective of this study was to explore the cognitive and social play of young Nigerian children in a crèche when they are introduced to novel play materials. Both cognitive and social play behaviours were observed during the play episodes with novel play materials. In concordance with categories presented in the literature review in chapter one, the following section will highlight the significance of these findings in terms of the cognitive and social development of children in this crèche. The results suggest that the introduction of play materials provoked action as observed in the children's behaviours. The chapter will conclude with a discussion on the limitations of the study, areas for further research, and the implications for educators and caregivers.

The current study revealed that the introduction of novel play materials elicited exploration and/or play behaviours in the children, ages 7- to 24-months-old, who participated in the study. The children interacted and engaged with the materials in various ways, including exploration by touching, tasting, looking at, or listening to the items; and play through functional, constructive, and dramatic means. Two behaviours that did not fall under the nested categories were also observed: simple social play and behaviours related to the adult-led group reading activity.

\section{Cognitive Development}

Exploration. Children have a propensity for exploration, which is believed to be the precursor to play (Hutt, 1979). Children explore their world using their senses. Although a variety of behaviours were observed, there were noticeable developmental differences in the

exploratory behaviours of the participants. The children 12-months and younger often explored the materials orally, even with materials like the sheer fabric, whereas the older children's 
explorations involved more tactile and visual methods. This finding is supported by Uzgiris and Hunt (1975) who stated that younger infants indiscriminately engaged in mouthing, striking and shaking objects, while children after 12-months of age were more selective with their modes of exploration. In one instance, Chantel, 14-months old, crawled over to the table where the playdough was placed. Although she pulled herself up to stand at the table, she did not reach out for the balls of playdough. Instead, she visually inspected the playdough. She was prelocomotive and required her hands to hold herself up at the table, which may have limited her interaction with the playdough. Although there were chairs at this table, she did not choose to sit down in order to free her hands. This highlights the importance of presenting play materials in areas that are easily accessible for all children who want to engage with them. Overall, the children in the present study revealed a wide variation of exploratory behaviours but generally showed progressive development with age as shown by Uzgiris and Hunt (1975).

All children, with the exception of Tia, 24-months-old, were observed in some type of solitary or parallel exploration with the novel play materials. It is possible that the play materials were not novel to Tia, so she did not need to explore them but rather could begin to play with them. Caution must be taken in order not to infer that older toddlers do not engage in exploratory behaviours. Older children do engage in exploration, but are able to process a limited amount of information quickly and then proceed to other play or tasks (Piaget \& Inhelder, 1967).

From the analysis of exploratory behaviours, three interesting discoveries were made. First, children spent more time exploring play materials that were multifaceted. The shakers were made from empty plastic water bottles that were filled with various items. These items comprised of different textures, weights, colours, and so forth. The shakers were the only objects that made a sound when the children shook them. Much of the time exploring the shaker was 
devoted to shaking and then peering inside. Behaviours such as peering intently at moving items can denote examination, which is an important cognitive process often observed during children's exploration. Another important implication of children's exploration of the shakers is that children begin to understand that their actions can produce an effect, which is reflected in the repetitive act of moving their arm and listening to the shakers. Piaget (1952) discussed similar observations regarding children who repeatedly perform the same act in a way that reflects and contributes to their developing understanding of cause and effect. In all, the children spent more than twice the amount of time investigating these shakers than they did exploring any of the other novel play materials. Because the children were pre-verbal, they were not able to explicitly confirm their reasoning for shaking the shakers. However, the findings suggest that the children's actions and behaviours denote serious inquisition regarding the bottle and the items in the bottle.

Second, two children of the same age had very different exploratory behaviours with the same materials. When the playdough was introduced, one child was eager to explore the material tactilely, while the other child was very hesitant. There are many possible reasons that could account for this difference, one of which could be differences in the children's' previous experiences (or lack thereof) with similar materials. Needham et al. (2002) assert that prior experience with a particular object or material allows children to engage in a greater number of explorations in a later situation. This could have been a possibility for these children. On the other hand, personal preference could also play a role in the differing degrees of interest. Amid current marketing claims promoting the cognitive benefits of playing with certain objects and materials, parents and caregivers should take care not to force children to play with objects in which they have no interest. In a social setting like a child care program, caregivers and 
educators should respect the individuality of each child and allow for exploration and engagement at the child's natural pace. In addition, introducing certain types of stimuli at different stages will ensure children have a wide-range of experiences for overall development and learning.

Third, children were very comfortable in their crèche and had familial-like relationships with the two caregivers, which may have contributed to the openness to explore novel materials. This type of familial relationship may reflect the cultural value within their crèche, in that the caregivers were extremely attentive to the children's needs and prioritized their comfort, perhaps over stimulation, as a value. This comfort with the caregivers was evident by the willingness of the children to leave their parents and go with the caregivers when the children arrived in the morning. The children, whether locomotive or pre-locomotive, immediately approached the novel play materials when they were introduced and explored them willingly. During the first few days of the data collection, some children stayed within close proximity of their caregivers, but once the play materials were presented, they eagerly explored them. Previous studies have shown that children that feel a sense of security and comfort with those in their child care setting are more likely to explore than those who do not (Goldschmied \& Jackson, 1994; Main, 1983). We found this to be the case in our study as well, and this speaks to the potential contributions that attentive caregiving may provide, despite a lesser value of stimulation within this age group. It may indeed challenge our notions of exactly how much stimulation, or play, is required in order for children to explore their world.

As children's exploratory behaviours become more systematic with age and experience, it is imperative that children are given the opportunities to explore many different kinds of objects and materials. Gibson (1988) asserts that the basis for classifying objects, and even learning 
about simple relationships between events, is through exploration. Then with more specialized exploration, leading to observable outcomes, children are able to learn about an object's affordances and, ultimately, what they can do with it. In the present study, this progression from exploration to play was most notable with the water bottle play objects, as the younger children engaged in more exploratory behaviours, whereas the eldest child used the bottle in her pretend play.

Play. Functional, pretend, and constructive play behaviours were observed during the introduction of the novel play materials. After exploratory behaviours, functional play behaviours were the most commonly observed in this study, occurring in children between the ages of 12- and 24-months. Once children are satisfied with their exploration of the object, they will begin to see how they can act on the object, signifying a level of control by the child (Hutt, 1976). Numerous studies support Hutt's (1976) claim that between the first and second year of life, children begin to play, experimenting to see what will happen when they act on objects (Gopnik, Meltzer, \& Kuhl, 2001; Hutt, 1979; Piaget, 1962).

Functional play in the earliest stages might include repeated actions or imitation that are exhibited for the physical sensation it evokes (Rubin, 2001), whereas later on, functional play may become more relational in nature (Garner \& Bergen, 2006). In the present study, various types of functional behaviours were observed, from repeatedly striking a drum on the floor to repeatedly rolling a plastic fruit toy off a plastic basket and onto the floor. In the latter case, the child incorporated more than one material and tilted the basket just at the right angle to cause the fruit to roll onto the floor. In play episodes in which one outcome requires multiple steps, there may be many cognitive processes involved such as arranging, reflecting, and observing. These 
cognitive processes should be fostered in early childhood as such abilities are required for healthy development.

Pretend play behaviours were also exhibited in simple forms. Kyle, 12-months, was engaging in pretend play, as he appeared to be ‘drinking' from a cup. This finding is supported by previous research that states that the simplest forms of pretend play occurs at approximately 1-year of age and is often directed to oneself (Fein, 1981). Pretend play with others develops after the first 12-months of age. The sequence of pretend play typically extends out towards other persona objects (e.g., stuffed animal used as the child’s baby) and eventually towards peers (Tamis-LeMonda \& Bornstein, 1991). Tia, 24-months, extended her pretend play behaviours to me, as she was pretending to do my hair with the water bottle that was filled with oil and water. Although I am not her peer and I did not join in on her pretend play, she did use my hair as a prop for her play. Since children's pretend play when they are between 24- to 36-months of age is reflective of social roles, it is possible that Tia was role playing what she has seen and/or experienced in her life (e.g. a hairstylist or a family member doing her hair). When the water bottle filled with liquid was introduced, Tia immediately used it in her pretend play role. Hughes (1991) argues that objects or props are vital in encouraging pretend play.

Finally, constructive play behaviours were observed with Zoey, 12-months, and Tia, 24months. The two children were using their objects to attain a goal. Tia was trying to put eight nesting cups in order. Through multiple attempts of putting various sized cups in different arrangements, she was eventually able to stack them in order. This process of trial and error involved many different cognitive processes, such as observing, sorting, organizing, hypothesizing, reflecting, and rearranging, to name a few. Zoey, 12-months, was engaged in an activity that was considered constructive play due to the "what-if" attitude that defined her 
behaviours. She was trying to put the lid on a small jam jar. However, she had not yet developed the fine motor skills to place the lid in place and then screw it closed. Instead, she struck the two pieces together and even pressed the two pieces together in her fist and then struck her hand on the floor. Between various attempts at banging the pieces together, she lined up the lid and jar as strategically as she possibly could, but to no avail. Although she was not able to place the lid on the jar, she displayed problem solving skills in her valiant attempts.

\section{Social Development}

Social Play. Parten’s (1932) social play categories were used in the coding scheme to observe children's social participation during the introduction of play materials. Due to the age of the participants, only the solitary play and parallel play categories were used for analysis. Another social play category that arose during the introduction of the play materials was simple social play (Howes \& Matheson, 1992). Simple social play is a category devised by Howes to explain scenarios in which children engage in similar activities, talk and smile with one another, give and receive toys, or participate in simple social interactions (Howes \& Matheson, 1992).

In this present study, solitary play was the most common social play category during the introduction of the play materials, which is unsurprising given the age of the participants. Other studies have shown that with the introduction of objects, children under one year of age were more engaged with the objects than with their peers (Eckerman \& Watley, 1977; Vandell \& Mueller, 1980). An inclination to explore likely contributes to these findings. As children grow and have more experiences, they become increasingly interested in objects that are new to them and after 12-months of age, this begins to include other children (Eckerman \& Watley, 1977). Parallel play behaviours were less frequent in this study. Despite the nature of the one-room setting, children at the crèche more often played or explored alone. This is likely due to the 
notion that parallel play is more prevalent among older toddlers and three-year-olds (Parten, 1932).

\section{Other}

Simple Social Play. Uncategorized play behaviours were found in several play episodes whereby children engaged in simple social play. In one situation, Zoey and Kyle, both 12months-old, and Tia, 24-months-old, were all striking their red plastic disposable cups on the dining table and chairs. Zoey initiated this behaviour and the other two imitated the same behaviour. The play behaviours indicated possible functional play, but the uniformity in actions among the three children showed that a unique type of social play was occurring. In one situation, Zoey and Kyle, both 12-months-old, and Tia, 24-months-old, would engage with one another by giving and taking cups and putting one's cup into that of another's. It seemed that one child initiated the act of taking another's cup and stacking it into her own, and the other children acted in similar ways.

More often than not, the children did not exhibit aggressive behaviours when others took their cups; rather they would find another cup or take their cup back and continue walking around. This is not to say conflicts did not arise at all amongst the children. Among the three children, however, more disagreements were seen between the two children of the same age, even though they were all involved in the same activity. Howes and Matheson (1992) claim that young children who have become familiar with peers through playgroups begin to show preferences for certain children. There are many reasons in which certain interactions between children seem more playful than others; however, it is possible that children in multi-age child care settings with fewer children develop specific social behaviours at a younger ages. For instance, McClellan and Kinsey (1997) found that children who had participated in a multi-age 
kindergarten showed more pro-social behaviours. Further investigations of simple social play among peers in child care programs may be useful in understanding how these relationships develop, particularly by looking at cultural influences that may affect children's interactions with one another.

Another interesting discovery is that of the six play episodes with the red disposable cups, only two of them involved play or exploration, while four of them resulted in simple social play. In this particular crèche, the group of children participating in simple social play behaviours were older than 12-months of age and these unanticipated and uncategorized simple social play behaviours occurred when the children were playing with the plastic disposable cups, which could be considered one of the least novel materials introduced to them during this study. As the children may have been familiar with plastic cups, they may not have been too interested in exploring or playing with them, but the presence of the cups may have encouraged specific social interactions among the children. In fact, Jacobson (1981) showed that after 14-months of age, children engage in more social interactions when play materials are available. Therefore, with these particular play materials, social interactions among the children were more prevalent. The level of social, as well as cognitive, play is influenced by the affordances of the object. Needless to say, other play materials introduced during the study were also not entirely novel for the children, but the objects were not used daily as a plastic cup would have been.

Adult-led Group Reading. Although the picture book was a novel object at the crèche, the findings from that adult-led group reading activity were unique in that the children's behaviours were likely dependent on the caregiver's. Since the caregiver was reading the story to the children, she guided the children through the pages instead of having the children engage with the book independently as they did with the other novel play materials. Despite this 
caregiver-led activity, the two older children attempted to flip through the pages of the books, showing interest in the object.

Roskos and Christie (2004) review of literacy and play studies concluded that "play provides settings that promote literacy activity, skills, and strategies” (p.116); thus a key step in promoting this type of play is making objects available that provoke literary play. A study by Christie and Enz (1992) showed that 4-year-olds engaged in pretend play by "reading” storybooks to stuffed animals was a predictor of language skill and reading readiness. If children have books with which they can freely engage, it may encourage literary play at a younger age.

There are limited studies on young children's object play in cultures outside Western societies. This present study has found developmental data that is consistent with those in previous studies, both from Western and non-Western societies. In Göncü et al.’s (2000) study with young children from India, Turkey, the USA, and Guatemala, they found that novel play materials elicited similar types of exploration among infants. This present study adds to the literature to show that young Nigerian infants and young toddlers also engaged in exploration of novel play materials in similar ways, first by first mouthing the objects and then exploring them using more tactile and visual inspections. Nevertheless, this does not mean young children’s object play is exactly the same across cultures. Although ages of skill acquisition may differ, there is consistency across studies detailing the progression from the beginning of exploration to complex pretend play and from solitary play to play with others (Fromberg \& Bergen, 2006).

The fact that the children in this present study did not have a lot of experience playing with materials and objects at their crèche did not deter them from engaging with them. Bloch (1984) found similar outcomes in her study with young Senegalese children. Although they did not have many toys, they were eager to engage in play materials and used common household 
items in their play. This current study also focused on creating objects for play using materials that were readily available, including those from nature. A key objective for caregivers and educators should be to source a variety of materials that would provoke various types of play in the children. Without considering cultural factors, this present study adds to evidence that sequential development of object play may exist. As factors such as culture influence a child's everyday life, further studies incorporating culture should be conducted.

To conclude, this study aimed to explore children's interaction and play with novel play materials. As few studies have been conducted in Nigeria with infants and toddlers regarding their play behaviours, this study was able to offer a glimpse into the exploration, play and social interactions of young children at their crèche. The findings show that children were eager to explore and play with novel objects that were introduced to them. They explored the materials using all their senses—-tasting, smelling, touching, looking at, and listening to the objects. They used the objects to further their own goals and wishes. With more children enrolled in out-ofhome child care programs and at a younger age, it is imperative that the child care programs offer stimulating and engaging environments, which will encourage optimal play experiences to foster overall development and learning. Through these varied and diverse play experiences and social interactions with peers and other adults, children's development will flourish, giving the child necessary skills to succeed in the future. To help promote healthy cognitive and social development in children, experiences and interactions with varied play materials at a young age is vital.

\section{Lessons Learned}

There were two main lessons learned from this experience. First, although the relationship between caregivers and the children focused predominantly on the fundamental 
needs of the children, including feeding, diaper changing, and safety, the familial bond between the children and the caregivers provided the necessary foundation for children's independent exploration and play. As mentioned above, children who feel a sense of safety and security with their caregivers are more likely to explore and engage (Goldschmied \& Jackson, 1994; Main, 1983). In this present study, the caregivers essentially filled the roles of "mama," which is the name the children used when addressing them. It seemed that the children trusted in the caregivers as they would their own families. For one, the children were open to our being in their crèche and played with the materials and us freely because they knew they could always turn to their caregivers if they needed. In a time when educators are frequently focused on teaching the next lesson, my experience at the crèche was a needed reminder that a child's overall health and well-being should be prioritized before academic goals and benchmarks. If a child feels safe and confident, they will engage in more varied play and interact with peers, all pertinent factors in healthy development.

Second, this study showed that stimulating and engaging play materials do not need to be expensive or elaborate, and rather, can often be gathered locally. Providing simple objects that can be easily created or found can add to the programming of a crèche, a nursery, or a school to provoke exploration and play in children, providing a productive means of engagement. In a child care setting such as a crèche where caregivers may not have plentiful materials or have not received educational training, simple play materials can enhance the role of the caregiver by providing another playful and stimulating connection between the child and the caregiver.

\section{Limitations}

There were several limitations regarding the study's methodology. For one, a lack of experience using video recording to document observations posed a disadvantage, affecting 
video quality. As the children were observed in their natural setting, the video should have encompassed the entire room; however, we needed to capture the children's behaviours and, often, intricate hand movements, so closer footage was also needed. Thus, there was a chance that certain behaviours were not observed if children were out of frame as we only had one video camera.

Second, being a participant-observer may affect the participants’ behaviours. Two days prior to data collection was not adequate for familiarizing myself with the children. Not only am I an 'outsider' researcher, but also a foreigner in their country, which could have been a disadvantage to some degree. For example, there is always the possibility that the children altered or censored their behaviours around me or were distracted by my presence as they interacted with the novel objects.

Another limitation is the relatively short period of data collection (4 weeks) and the low number of participants. A longer data collection period may have generated more data for interpretation.

Lastly, another limitation to this study could have been the use of a priori categories for analysis that were established based on Western categories of analysis. There is a chance of omitting details that may be relevant as a result of using pre-established codes. However, given the purpose of this study to observe specific types of children's play with objects, the coding scheme was sufficient. Future studies could look to a more data-driven approach to analysis such as thematic coding. In this way, themes that are specific to a particular culture may emerge.

\section{Future Research}

The conceptual framework, which integrated cognitive and social play, along with the coding scheme should continue to be used in future studies to observe young children's play 
behaviours in their child care program. Based on the limitations of this study, further studies should be conducted. As the present study looked at young Nigerian children's behaviours as they pertained to novel play materials, future studies could investigate Nigerian children's engagement and play with materials with which they are familiar to see if, and how, play and social behaviours continue or change. In addition, other possible adaptations to the coding scheme could be made to account for specific types of play that may be more culturally specific or less common in one culture compared to another. Further, it may be worthwhile to examine the interactions between the children and their caregivers during the introduction of novel play materials to see how the caregivers' actions may influence the children's exploration and play with the materials. This could lead to a more culturally relevant analysis. As noted above, a thematic coding scheme could be used to identify important themes within this culture. Lastly, given that the study was conducted with children in an urban setting, it would be interesting to compare exploratory and play behaviours in children from other urban cities and rural communities to see if similar cognitive and social play behaviours arise.

\section{Implications}

In this study, play materials facilitated both cognitive and social play among infants and toddlers, ages 7- to 24-months. The study's main implication for practice is that children's exploration of play materials require little resources. This alone is not novel, as it has been well documented that children in under-resourced environments will creatively manufacture objects for play (Bartie et al., 2015; Bloch, 1984). However, a large-scale introduction of simple play objects within early childhood settings may help to implement elements of Nigeria’s ambitious educational policy that is currently hindered by resource scarcity. Within under-resourced settings, in which certified early childhood educators are few, the possibility of learning through 
play with simple objects facilitated by caregivers could be monumental. Many of the play objects were unadorned, homemade or gathered in the community, allowing for easy replication and use regardless of the location. Local materials and aesthetics can all be incorporated into the design to ensure that individual cultures are promoted.

The caregivers were equally as excited to integrate materials into their crèche. By offering workshops on how to incorporate play materials into the children's play, the caregivers can expand their roles to facilitating learning through guided play. An argument still stands for the positive influence that play materials have in an early years setting. Based on the findings of this study, the use of play materials in this crèche was invaluable. Not only do play materials allow for an affordable means of fostering curiosity and exploration, but when other resources are scarce, children can engage in play with and exploration of simple play materials to enhance their overall development.

\section{Conclusion}

The current study demonstrated that young Nigerian children, ages 7- to 24-months, engaged in exploratory and play behaviours when introduced to novel play materials at their crèche. Despite the scarcity of available play materials, caregivers and the research team were able to collaborate, brainstorm, and work together to acquire materials and objects with which children can play. This exploration and play with objects is supports healthy social and cognitive development in children. This study offered some insight into young children's object play experiences in their crèche. Studies should continue to be conducted with young children in different cities and towns in Nigeria in order to have a better understanding of children's play in various settings. More importantly, however, researchers, educators, caregivers, parents, 
politicians, and all citizens should endeavor to provide the basic necessities required for children's play. 
Appendices

Appendix A

Figure 1

Crèche Floor plan (Abuja, Nigeria)

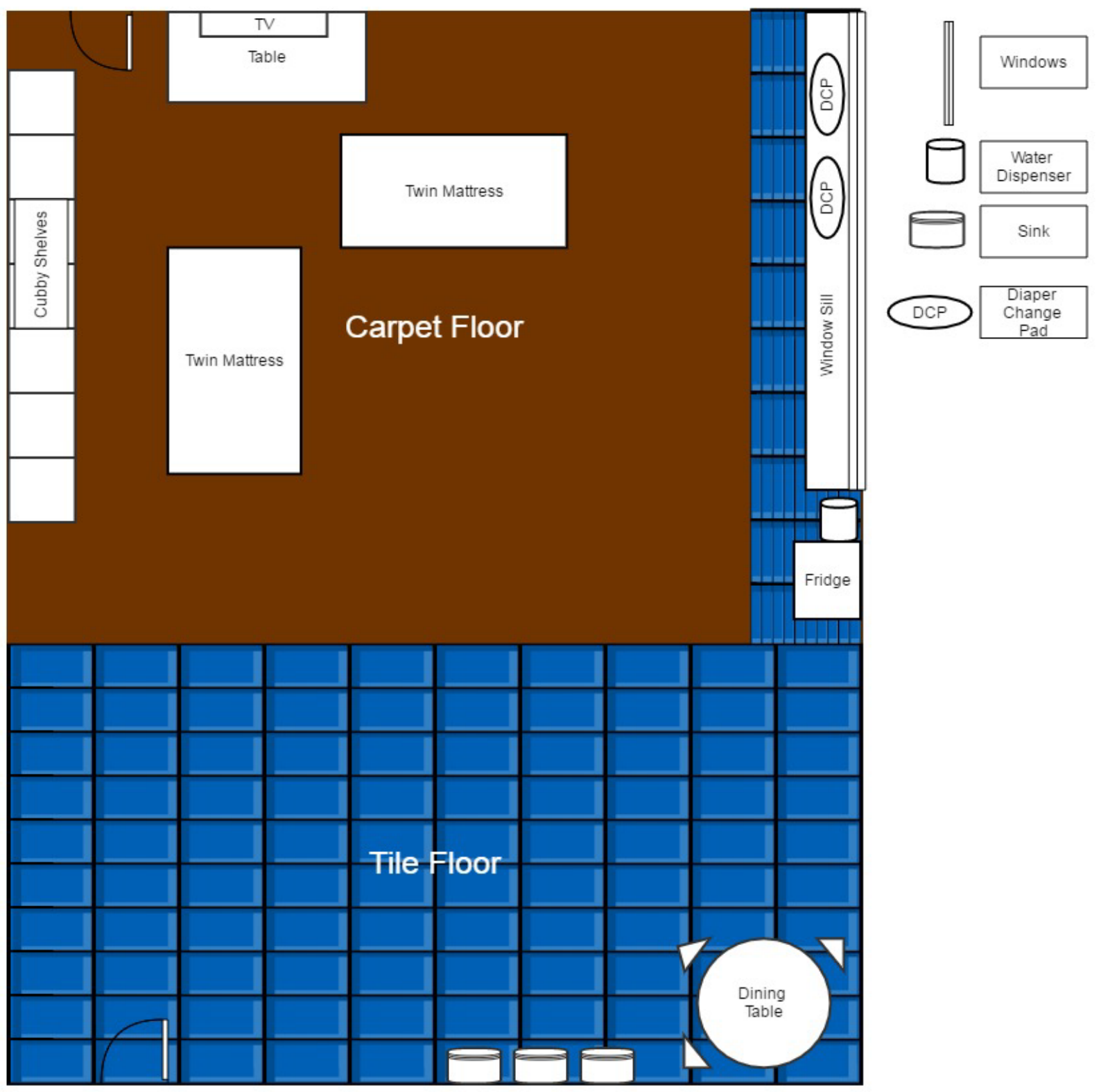




\section{Appendix B}

Table 1

\section{Materials}

\begin{tabular}{|c|c|c|}
\hline Day & Play Material Introduced & Play Material Introduced By \\
\hline 1 & None; observed naturalistic play & - \\
\hline 2 & None; observed naturalistic play & - \\
\hline 3 & $\begin{array}{l}\text { A.M.: } 7 \text { Water bottles half-filled with one of the } \\
\text { following items: green seeds, brown seeds, green leaves, } \\
\text { yellow leaves, yellow corn kernels, dyed corn kernels, } \\
\text { small pebbles }\end{array}$ & researcher and caregiver \\
\hline & P.M.: Children’s picture book & caregiver \\
\hline 4 & 12 Red plastic disposable cups & caregiver \\
\hline 5 & None & - \\
\hline 6 & $\begin{array}{l}\text { A.M.: } 2 \text { Water bottle half-filled with oil and coloured } \\
\text { water }\end{array}$ & caregiver \\
\hline & P.M.: 10 Small jam jars and lids & researcher \\
\hline 7 & None & - \\
\hline 8 & $\begin{array}{l}\text { "Treasure Bowl” (Big wooden bowl containing an } \\
\text { African hand drum, a small dried gourd, a palm-sized } \\
\text { wooden container w/lid, a palm-sized leather container } \\
\text { w/lid, } 2 \text { handmade cardboard boxes covered in } \\
\text { laminating paper, } 6 \text { red wooden bangles/bracelets, } 4 \\
\text { small jam jars w/lids, a water bottle filled with seeds, a } \\
\text { flipbook of laminated photos, a small wooden bowl, a } \\
\text { wooden bristle beard brush }\end{array}$ & caregiver \\
\hline 9 & A.M.: Sheer orange scarf (1 yard X 4 yards) & researcher \\
\hline & P.M.: Drawing table with paper and crayons & researcher \\
\hline 10 & Plastic fruit pieces stored in a large plastic basket & caregiver \\
\hline 11 & None & - \\
\hline 12 & None & - \\
\hline 13 & None & - \\
\hline 14 & Homemade playdough & caregiver and researcher \\
\hline 15 & None & - \\
\hline 16 & Plastic nesting cups (8-cup set) & researcher \\
\hline
\end{tabular}




\section{Appendix C}

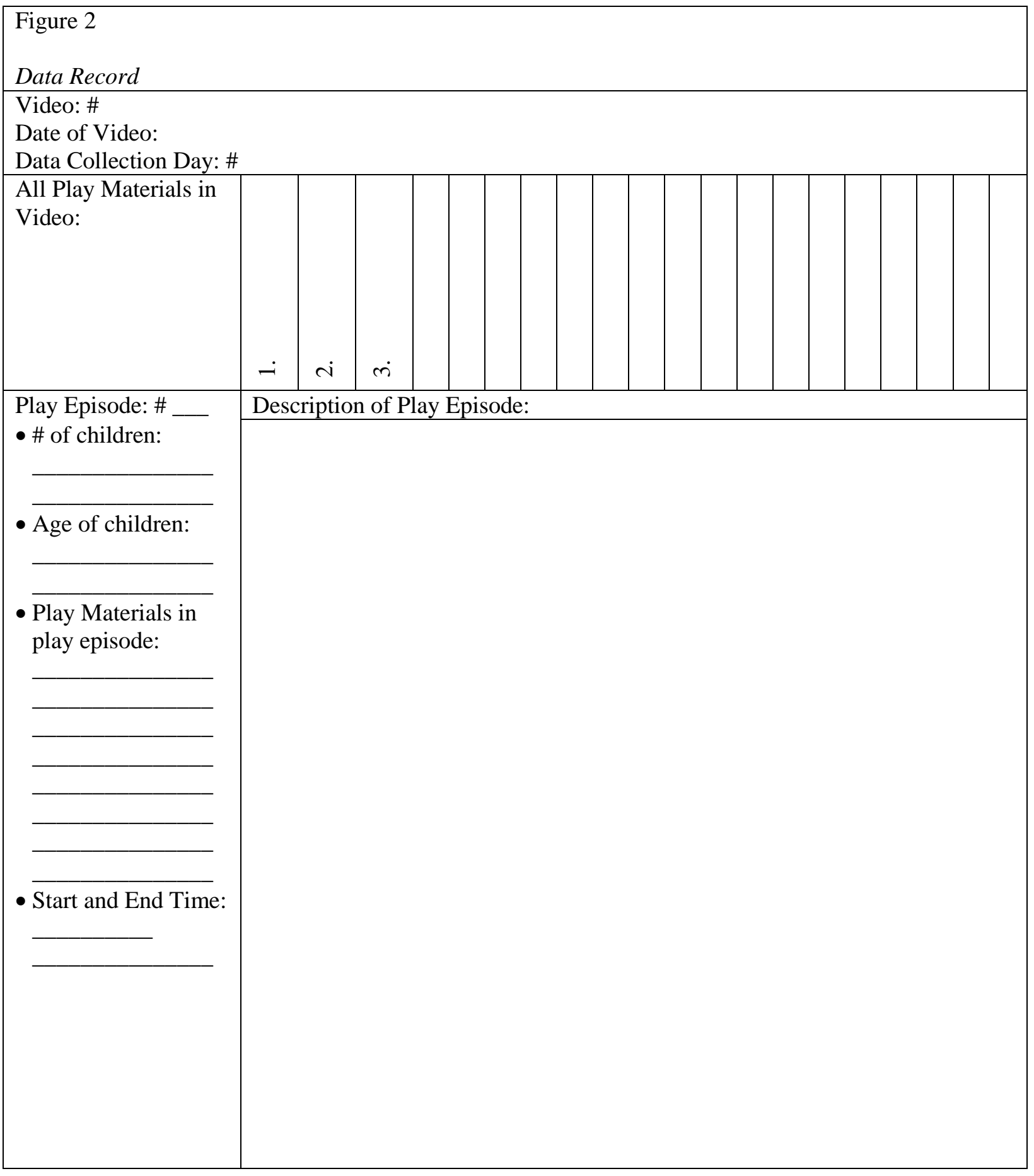




\section{Appendix D}

\begin{tabular}{|c|c|c|c|}
\hline \multicolumn{4}{|c|}{\begin{tabular}{|l} 
Figure 3 \\
Object Play Coding Scheme \\
\end{tabular}} \\
\hline \multicolumn{2}{|c|}{ Cognitive Play } & \multicolumn{2}{|c|}{ Social Play } \\
\hline & & Solitary & Parallel \\
\hline \multicolumn{2}{|c|}{ Exploration } & & \\
\hline \multirow{3}{*}{ Play } & Functional & & \\
\hline & Pretend & & \\
\hline & Constructive & & \\
\hline
\end{tabular}




\section{Appendix E}

Table $2 \quad$ Note

Frequencies of Coded Behaviour

\begin{tabular}{|c|c|c|c|c|}
\hline Behaviour & & Social & & Total \\
\hline & Solitary & $\underline{\text { Parallel }}$ & Other & \multirow[b]{2}{*}{12} \\
\hline Exploration & 6 & 6 & & \\
\hline \multicolumn{5}{|l|}{ Cognitive Play } \\
\hline Functional & 2 & 3 & & 5 \\
\hline Pretend & 3 & 0 & & 3 \\
\hline \multirow[t]{2}{*}{ Constructive } & 3 & 0 & & 3 \\
\hline & & & 6 & 6 \\
\hline
\end{tabular}

al play' and 'adult-led group reading' 


\section{References}

Baldwin, D. A., Markman, E. M., \& Melartin, R. L. (1993). Infants' ability to draw inferences about nonobvious object properties: Evidence from exploratory play. Child development, 64(3), 711-728.

Bartie, M., Dunnell, A., Kaplan, J., Oosthuizen, D., Smit, D., Dyk, A., Cloete, L., \& Duvenage, M. (2015). The play experiences of preschool children from a low-socio- economic rural community in Worcester, South Africa. Occupational Therapy International, 23(2), 91-102.

Bergen, D. (1998). Readings from play as a learning medium. Olney, MD: Association for Childhood Education International.

Best, A. (2007). Representing Youth. New York, NY: University Press

Bigelow, A. E., MacLean, K., \& Proctor, J. (2004). The role of joint attention in the development of infants’ play with objects. Developmental Science, 7(5), 518-526.

Bloch, M. N. (1984). Play materials: Considerations from a West African setting. Childhood Education, 60(5), 345.

Bronfenbrenner, U. (1979). Contexts of child rearing: Problems and prospects. American psychologist, 34(10), 844.

Brownell, C. A., Ramani, G. B., \& Zerwas, S. (2006). Becoming a social partner with peers: Cooperation and social understanding in one- and two- year- olds. Child Development, 77(4), 803-821.

Bucknall, S. (2014). Doing qualitative research with children and young people. In A. Clark, R. Flewitt, \& M. Hammersley (Eds.), Understanding research with children and young people (pp. 69-84). [Place of publication not identified]: Sage Publications. 
Bundy, A.C., Luckett, T., Tranter, P.J., Naughton, G.A., Wyver, S.R., Ragen, J., \& Spies, G. (2009). The risk is that there is 'no risk': A simple, innovative intervention to increase children's activity levels. International Journal of Early Years Education, 17(1), 33-45.

Butler, K. \& Gilson, D. (2016). What's Your Baby's Carbon Footprint?. Mother Jones. Retrieved 20 April 2016, from http://www.motherjones.com/environment/2008/04/whats-your babys-carbon-footprint

Chambers, C. T., \& Johnston, C. (2002). Developmental differences in children's use of rating scales. Journal of Pediatric Psychology, 27(1), 27-36.

Chernova, Y. (2016, Mar 18). Play-based education network Tinkergarten gets support from Omidyar. The Wall Street Journal. Retrieved from http://blogs.wsj.com/venturecapital/2016/03/18/play-based-education-network$\underline{\text { tinkergarten-gets-support-from-omidyar/ }}$

Christie, J. F., \& Enz, B. (1992). The effects of literacy play interventions on preschoolers' play patterns and literacy development. Early Education and Development, 3(3), 205-220.

Collard, R.R. (1979). Exploration and play. In B. Sutton-Smith (Ed.), Play and learning (pp. 4568). New York, NY: Gardner.

Cooney, M.H. (2004). Is play important? Guatemalan kindergartners’ classroom experiences and their parents' and teachers’ perceptions of learning through play. Journal of Research in Childhood Education, 18(4), 261-277.

Coplan, R. J., Rubin, K. H., \& Findlay, L. C. (2006). Social and nonsocial play. Play from birth to twelve: Contexts, perspectives, and meanings, 2, 75-86.

Corsaro, W.A. 1985. Friendship and Peer culture in the early years. Norwood, NJ: Ablex. 
Creswell, J.W. (2013). Research Design: Qualitative, Quantitative, and Mixed Methods Approaches. ( $4^{\text {th }}$ ed.). Thousand Oaks, CA: Sage Publications.

DeLoache, J. S., Pierroutsakos, S. L., Uttal, D. H., Rosengren, K. S., \& Gottlieb, A. (1998). Grasping the nature of pictures. Psychological Science, 9(3), 205-210.

DeVries, R. (2006). Games with rules. In D.P. Fromberg \& D. Bergen (Eds.), Play from birth to twelve: Contexts, perspectives, and meanings (pp. 119-125). New York, NY: Routledge.

Deynoot-Schaub, M. J. G., \& Riksen-Walraven, J. M. (2006). Peer contacts of 15- month- olds in childcare: Links with child temperament, parent-child interaction and quality of childcare. Social Development, 15(4), 709-729.

Early Learning for Every Child Today. (2007). Retrieved 17 March 2016, from http://www.edu.gov.on.ca/childcare/oelf/continuum/continuum.pdf

Early Childhood Development Initiative. (2016). Early childhood development (ECD) teaching methodologies: Reggio Emilia and other child centred approaches. Abuja, Nigeria: ECDI, UNICEF, NCCE.

Eckerman, C. O., \& Whatley, J. L. (1977). Toys and social interaction between infant peers. Child Development, 1645-1656.

Edwards, C., Gandini, L., \& Forman, G. (Eds.). (2011). The hundred languages of children: The Reggio Emilia experience in transformation. ( $3^{\text {rd }}$ ed.). Santa Barbara, CA: ABC-CLIO.

Fein, G. G. (1981). Pretend play in childhood: An integrative review. Child Development, 52(4), 1095-1118.

Forbes, R. (2004). Beginning to play: Young children from birth to three. Maidenhead, UK: McGraw-Hill Education. 
Forman, G. E., \& Hill, F. (1984). Constructive play: Applying Piaget in the preschool. Menlo Park, CA: Addison-Wesley.

Fraser, S., \& Gestwicki, C. (2002). Authentic childhood: Exploring Reggio Emilia in the classroom. Albany, NY: Delmar/Thomson Learning.

Fromberg, D. P., \& Bergen, D. (2006). Play from birth to twelve: Contexts, perspectives, and meanings. New York: NY: Taylor \& Francis.

Garner, B.P., \& Bergen, D. (2006). Play development from birth to age four. In D.P. Fromberg \& D. Bergen (Eds.), Play from birth to twelve: Contexts, perspectives, and meanings (pp. 119-126). New York, NY: Routledge.

Gaskins, S., Haight, W., \& Lancy, D.F. (2007). The cultural construction of play. In A. Göncü, and S. Gaskins (Eds.), Play and development: Evolutionary, sociocultural, and functional perspectives (pp. 179-202). Mahwah, NJ: Erlbaum.

Gillen, J., \& Cameron, C. A. (2010). International perspectives on early childhood research: a day in the life. Palgrave Macmillan.

Göncü, A., Mistry, J., \& Mosier, C. (2000). Cultural variations in the play of toddlers. International Journal of Behavioral Development, 24(3), 321-329.

Gopnik, A., Meltzoff, A., \& Kuhl, P. (2001). The scientist in the crib: What early learning tells us about the mind. New York, NY:

Graue, M. E., \& Walsh, D. J. (1998). Studying children in context: Theories, methods, and ethics. Sage Publications.

Hammersley, M. (2014). Research design. In A. Clark, R. Flewitt, M. Hammersley, \& M. Robb (Eds.), Understanding research with children and young people (pp. 107-121). [Place of publication not identified]: Sage Publications. 
Hancock, R., Gillen, J., \& Pinto, G. (2010). Using video technology. InInternational perspectives on early childhood research (pp. 35-58). Palgrave Macmillan UK.

Harkness, S. (2002). Culture and social development: Explanations and evidence. In P.K. Smith and C.H. Hart (Eds.), Blackwell handbook of social development (pp. 60-77). Oxford, UK: Blackwell.

Hatch, J.A. (2007). Early childhood qualitative research. New York, NY: Routledge.

Hirsh-Pasek, K., Golinkoff, R., Berk, L., \& Singer, D.G. (2009). A mandate for playful learning in preschool: Presenting the evidence. New York, NY: Oxford Learning Press.

Hoyte, F., Degotardi, S., \& Torr, J. (2015). What it is all about: Topic choices in young children's play. International Journal of Play, 4(2), 136-148.

Howes, C., \& Matheson, C. C. (1992). Sequences in the development of competent play with peers: Social and social pretend play. Developmental Psychology, 28(5), 961.

Howes, C., \& Phillipsen, L. (1998). Continuity in children's relations with peers. Social Development, 7(3), 340-349.

Howes, C., Unger, O., \& Seidner, L. B. (1989). Social pretend play in toddlers: Parallels with social play and with solitary pretend. Child Development, 77-84.

Hughes, F.P. (1999). Children, play, and development. Boston, MA: Allyn \& Bacon.

Hutt, C. (1979). Exploration and play. In B. Sutton-Smith (Ed.), Play and learning (pp. 174194). New York, NY: Gardner.

Ishigaki, E. H., \& Lin, J. (1999). A comparative study of preschool teachers’ attitudes: Towards ‘children’s right to play’ in Japan, China and Korea. International Journal of Early Childhood, 31(1), 40-47. 
Jacobson, J. L. (1981). The role of inanimate objects in early peer interaction. Child Development, 618-626.

Johnson, V., Hart, R., \& Colwell, J. (2014). Steps to engaging young children in research. Volume 1: The guide.

Kamii, C., \& DeVries, R. (1980). Group games in early education: Implications of Piaget's theory. Washington, DC: NAEYC

Kotulak, R. (1997). Inside the brain: Revolutionary discoveries of how the mind works. Kansas City, MO: Andrews McMeel Publishing.

L'Abate, L. (2009). The Praeger handbook of play across the life cycle. Santa Barbara, CA: Praeger/ABC-CLIO.

Main, M. (1983). Exploration, play, and cognitive functioning related to infant-mother attachment. Infant Behavior and Development, 6(2-3), 167-174.

Mayes, L. C., Carter, A. S., \& Stubbe, D. (1993). Individual differences in exploratory behavior in the second year of life. Infant Behavior and Development, 16(3), 269-284.

McClellan, D. E., \& Kinsey, S. (1997, April). Children's social behavior in relationship to participation in mixed-age or same-age classrooms. Paper presented at the 1997 Biennial Meeting of the Society of Research in Child Development (SRCD). Washington, DC.

Morgenthaler, S.K. (2006). The meaning in play with objects. In D.P. Fromberg \& D. Bergen (Eds.), Play from birth to twelve: Contexts, perspectives, and meanings (pp. 65-74). New York, NY: Routledge.

Needham, A., Barrett, T., \& Peterman, K. (2002). A pick-me-up for infants’ exploratory skills: Early simulated experiences reaching for objects using ‘sticky mittens' enhances young infants’ object exploration skills. Infant Behavior and Development, 25(3), 279-295. 
Ness, D., \& Farenga, S. J. (2016). Blocks, Bricks, and Planks: Relationships between Affordance and Visuo-Spatial Constructive Play Objects. American Journal of Play, 8(2), 201-227.

Nicholson, J., Shimpi, P.M., Kurnik, J., Carducci, C., \& Jevgjovikj, M. (2014). Listening to children's perspectives on play across the lifespan: Children's right to inform adults' discussions of contemporary play. International Journal Of Play, 3(2), 136-156. http://dx.doi.org/10.1080/21594937.2014.937963

Nwankwo, F. (2015). Play materials and pupils development of social skills in pre-primary schools in Abia State, Nigeria. International Journal of Arts \& Sciences, 8(8), 387-402.

Ogunyemi, F. T., \& Ragpot, L. (2015). Work and play in early childhood education: Views from Nigeria and South Africa. South African Journal of Childhood Education, 5(3), 1-7.

Parten, M. B. (1932). Social participation among pre-school children. The journal of abnormal and social psychology, 27(3), 243.

Pellegrini, A. (2009). The role of play in human development. New York, NY: Oxford University Press.

Piaget, J. (1952). The origins of intelligence in children. New York, NY: International Universities Press.

Piaget, J. (1962). Play, dreams and imitation in childhood. London, UK: Routledge \& Kegan Paul.

Play. (2016). In The Cambridge Dictionary. Retrieved from http://dictionary.cambridge.org/dictionary/english/play

Roskos, K. \& Christie, J. (2004). Examining the play-literacy interface: A critical review and future directions. In E.F. Zigler, D.G. Singer, \& S.J. Bishop-Josef (Eds.), Children's play: The roots of reading, (pp.116-124). Washington, DC: Zero to Three 
Rubin, K. H. (2001). The play observation scale (POS). College Park, MD: University of Maryland.

Rubin, K.H., Coplan, R.J, Chen, X., Buskirk, A., \& Wojslawowicz, J. (2005). Peer relationships in childhood. In M. Bornstein \& M. Lamb (Eds.), Developmental psychology: An advanced textbook ( $5^{\text {th }}$ ed.), (pp.469-512). Hillsdale, NJ: Erlbaum.

Ruff, H. A., \& Lawson, K. R. (1990). Development of sustained, focused attention in young children during free play. Developmental Psychology, 26(1), 85-93.

Santer, J., \& Griffiths, C. (2007). Free play in early childhood: A literature review. National Children's Bureau.

Smilansky, S. (1968). The effects of sociodramatic play on disadvantaged preschool children. New York, NY: Wiley.

Smilansky, S., \& Shefatya, L. (1990). Facilitating play: A medium for promoting cognitive, socio-emotional and academic development in young children. Silver Spring, MD: Psychosocial \& Educational Publications.

Smith, P.K. (2005). Social and pretend play in children. In A.D. Pellegrini \& P.K. Smith (Eds.), The nature of play: Great apes and humans (pp. 173-212). New York, NY; Guilford Press.

Strong-Wilson, T., \& Ellis, J. (2007). Children and place: Reggio Emilia's environment as third teacher. Theory into Practice, 46(1), 40-47.

Sutton-Smith, B. (1979). Play and learning. New York, NY: Gardner Press

Thorp, M. (2003). A time to play: Playing, growing and learning in the first three years of life. Paper presented at Debating Play Conference, London, UK. 
Trawick-Smith, J. (2014). The physical play and motor development of young children: A review of literature and implications for practice. Retrieved from the web on, 3, 12-16.

Trawick-Smith, J., Russell, H., \& Swaminathan, S. (2011). Measuring the effects of toys on the problem-solving, creative and social behaviours of preschool children. Early Child Development and Care, 181(7), 909-927.

Trawick-Smith, J., Wolff, J., Koschel, M., \& Vallarelli, J. (2015). Effects of toys on the play quality of preschool children: Influence of gender, ethnicity, and socioeconomic status. Early Childhood Education Journal, 43(4), 249-256.

United Nations. (1989). Convention on the Rights of the Child.

Uzgiris, I., \& Hunt, J.M. (1975). Assessment in infancy. Urbana, IL: University of Illinois Press. Willats, P. (1983). Effects of object novelty on the visual and manual exploration of infants. Infants Behaviour and Development, 6(2), 145-149.

Williams, S. T., Mastergeorge, A. M., \& Ontai, L. L. (2010). Caregiver involvement in infant peer interactions: Scaffolding in a social context. Early Childhood Research Quarterly, 25(2), 251-266. 